\title{
Modelling cost-effective pathways for natural gas infrastructure: A southern Brazil case study
}

Iván García Kerdan ${ }^{\mathrm{a},{ }^{*}}$, Francisca Jalil-Vega ${ }^{\mathrm{a}}$, James Toole ${ }^{\mathrm{a}}$, Sachin Gulati ${ }^{\mathrm{a}}$, Sara Giarola ${ }^{\mathrm{b}}$, Adam Hawkes $^{\mathrm{a}}$

${ }^{a}$ Department of Chemical Engineering, Imperial College London, United Kingdom

${ }^{\mathrm{b}}$ Department of Earth Science \& Engineering, Imperial College London, United Kingdom

\section{ABSTRACT}

Currently, natural gas in Brazil represents around $12.9 \%$ of the primary energy supply, with consistent annual growth during the last decade. However, Brazil is entering a time of uncertainty regarding future gas supply, mainly as import from Bolivia is being renegotiated. As such, diversification of gas supply sources and routes need to be considered. Energy systems and infrastructure models are essential tools in assisting energy planning decisions and policy programmes at regional and international levels. In this study, a novel combination of a simulationbased integrated assessment model (MUSE-South_Brazil) and the recently-developed Gas INfrastructure Optimisation model (GINO) is presented. The Brazilian region represented by the five southern states served by the Bolivian gas pipeline (GASBOL) has been investigated. Modelled projections suggest that regional gas demand would increase from $38.8 \mathrm{mcm} /$ day in 2015 to 104.3 $\mathrm{mcm} /$ day by 2050 , mainly driven by the increasing demand in the industry and power sectors. Therefore existing regional gas infrastructure would be insufficient to cover future demands. Three different renegotiation scenarios between Brazil and Bolivia were modelled, obtaining distinct costoptimal infrastructure expansion pathways. Depending on the scenario, the model expects gas demand to be covered by other supply options, such as an increase in pre-salt production, LNG imports and imports from a new Argentinian pipeline.

\section{KEYWORDS}

Energy systems model; optimisation; gas infrastructure; infrastructure cost; natural gas; Brazil

\author{
* Corresponding author \\ Email address: i.garcia-kerdan@imperial.ac.uk (Ivan Garcia Kerdan); Tel: +44 (0)7867798730
}




\section{Nomenclature}

$\begin{array}{lll}\text { Sets } & & \\ g & \text { Zones } & 1,2, . .13 \\ \text { ipg } & \text { Processing facility type } & N G: \text { Natural gas } \\ & & L N G: \text { Liquefied natural gas } \\ & & U P: \text { Unprocessed natural gas } \\ \text { ipr } & \text { Production facility type } & R G: \text { Regasification of } L N G \\ & & L F: \text { Liquefaction } N G \\ & & N G P: \text { Natural gas production from } U P \\ & & B G P: \text { Biogas production } \\ \text { isf } & \text { Storage facility type } & A G: \text { Above ground } \\ & & U G: \text { Underground } \\ & & U P: \text { Unprocessed natural gas } \\ i t r & & \text { Truck: Truck } \\ t & \text { Freight transport type } & 2020,2025, \ldots, 2050\end{array}$

Variables

WIN $N_{\text {i isf } t} \quad 1$ if there is an inflow of gas form $i$ into a storage facility isf in time period $t$ in zone $g, 0$ if not

WOUT gi isf $t \quad 1$ if there is an outflow of gas form $i$ into a storage facility is $f$ in time period $t$ in zone $g, 0$ if not

$X 1_{g \text { it }}$

$X 2_{g}$ it

$Y 1_{g t}$

$Y 2_{g t}$

$Y 3_{g} g^{\prime} i t$

$Z 1_{\text {gipt } t}$

$Z 2_{\text {giprt }}$

$Z 3_{\text {giprt }}$

$Z 4_{\text {g ipr } t}$

$Z 5_{g i p r}$

1 if zone $g$ is importing gas form $i$ in time period $t$ in, 0 if not

1 if zone $g$ is exporting gas form $i$ in time period $t$ in, 0 if not

1 if a pumping station is built for transporting gas in time period $t$ in zone $g, 0$ if not

1 if a pumping station exists in time period $t$ in zone $g, 0$ if not

1 if there is a flow of gas $i$ in time period $t$ from zone $g$ to zone $g^{\prime}, 0$ if not

1 if production facility ipr in zone $g$ is ready for production in time period $t, 0$ if not

1 if production facility ipr in zone $g$ is operating in time period $t, 0$ if not

1 if production facility ipr in zone $g$ changes from not operating in time period $t-1$ to operating in $t, 0$ if not.

1 if production facility ipr in zone $g$ changes from operating in time period $t-1$ to not operating in $t, 0$ if not.

1 if production facility ipr exists in zone $g$ in time period $t, 0$ if not.

$A N T_{g \text { itr } t}$
$N P_{g g^{\prime} i t}$
$N P A_{g g^{\prime} i}$
$N P G_{g \text { ipg } t}$

Integer variables

Number available transport units in time period $t$ of type itr in zone $g$ Total number of pipelines for gas form $i$ in time period $t$ that connect zone $g$ with zone $g^{\prime}$

Number of new pipelines for gas form $i$ added in time period $t$ that connect zone $g$ with zone $g^{\prime}$

Number of new processing facilities installed in time period $t$ of type ipg in zone $g$ 
$N S_{g}$ i isf $t$

$N T P_{\text {gitr } t}$

$A P_{g \text { ipr } t}$

$C A P E S_{g} i$ isf $t$

CAPS $_{g}$ i isf $t$

$C E P G_{g \text { ipg } t}$

$C P G_{g i p g}$

$C T J_{g} g^{\prime} i$ itr $t$

$E R_{t}$

IC $C_{t}$

$P G C C_{t}$

$\mathrm{PGOC}_{t}$

$P G R_{g}$ ipg $t$

${ }_{P R C} C_{t}$

$\mathrm{PROC}_{t}$

$Q E_{g i t}$

$Q F_{g} g^{\prime} i$ itr $t$

$Q I_{\text {git }}$

$Q P_{g g^{\prime} i t}$

QSIN $_{g \text { i isf } t}$

QSOUT $_{g}$ i isf $t$

$S C C_{t}$

$S O C_{t}$

$T C C_{t}$

TOC $_{t}$

$\mathrm{TRCC}_{t}$

TROC $_{t}$

$T C_{t}$

$T D C$

$V R_{g \text { ipr }}$

$V S_{g i \text { isf } t}$

\section{Parameters}

AvSpeed $_{\text {itr }}$

$b$

c

$\operatorname{CapP}_{i}$

CapTr $_{i t r}$

Demand $_{\mathrm{t}}$

DistanceF $g_{g}{ }^{\prime}$ itr
Number of new storage facilities installed in zone $g$ of type is $f$ in time period $t$

Number of new transport units purchased in time period $t$ of type itr in zone $g$

\section{Continuous variables}

Production rate of unprocessed natural gas $(U P)$ by production facility ipr in zone $g$ in time period $t$

Total capacity expansion of storage facility of type is $f$ available in time period $t$ in zone $g$

Maximum capacity of storage facility of type is $f$ storing natural gas form $i$ in time period $t$ in zone $g$

Capacity expansion of processing facilities in time period $t$ of type ipg in zone $g$

Maximum capacity of processing facilities of type ipg in time period $t$ in zone $g$

Volume of gas form $i$ transported by freight mode itr between zone $g$ and zone $g^{\prime}$ in time period $t$

Total revenues from gas exports in time period $t$

Total cost of gas imports in time period $t$

Total capital cost of processing facilities in time period $t$

Total operating cost of processing facilities in time period $t$

Processing flow rate of processing facilities of type ipg in time period $t$ in zone $g$, in terms of produced flow

Total capital cost of production of unprocessed gas in time period $t$

Total operating cost of production of unprocessed gas in time period $t$

Flowrate of gas form $i$ exported from zone $g$ in time period $t$

Flowrate of gas form $i$ from transported by freight mode itr from zone $g$ to $g$ 'in time period $t$

Flowrate of gas form $i$ imported into zone $g$ in time period $t$

Flowrate of gas form $i$ from zone $g$ to $g$ 'in time period $t$

Flowrate of gas form $i$ entering storage type is $f$ in zone $g$ in time period $t$

Flowrate of gas form $i$ exiting storage type is $f$ in zone $g$ in time period

Total capital cost of new storage facilities in time period $t$

Total operating cost of storage facilities in time period $t$

Total capital cost of new pipeline infrastructure in time period $t$

Total operating cost of pipeline infrastructure in time period $t$

Total capital cost of new freight transport units in time period $t$

Total operating cost of freight transport units in time period $t$

Total capital and operating cost in time period $t$

Total discounted cost of supply chain over modelled time horizon

Available reserves for production facility ipr in zone $g$ in time period $t$

Total volume of gas form $i$ stored in storage facility of type is $f$ in time period $t$ in zone $g$

Average speed of transport mode itr

Minimum fraction of total capacity that a storage facility must utilise

Minimum fraction of gas demand that needs to be stored

Flow capacity of a single pipeline to carry gas form $i$

Capacity of a single transport unit of transport mode $i t r$

Gas demand in zone $g$ in time period $t$

Distance travelled by transport mode itr from zone $g$ to zone $g^{\prime}$ 


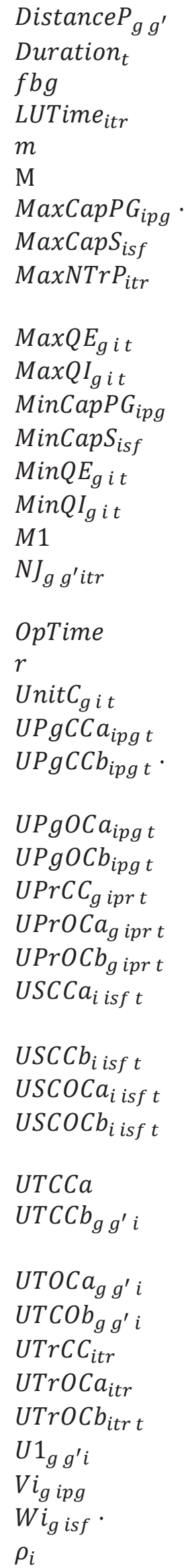

Pipeline distance from zone $g$ to zone $g^{\prime}$

Duration of time period $t$

Maximum allowable biogas fraction in gas stream

Total loading and unloading type of transport mode itr

Proportionality constant

Big M parameter

Maximum flow capacity of a single processing facility of type ipg Maximum storage capacity of a single storage facility of type is $f$

Maximum number of units of transport mode itr that can be purchased in one time period

Maximum exports flowrate of gas form $i$ in zone $g$ in time period $t$

Maximum imports flowrate of gas form $i$ in zone $g$ in time period $t$

Minimum flow capacity of a single processing facility of type ipg

Minimum storage capacity of a single storage facility of type is $f$

Minimum exports flowrate of gas form $i$ in zone $g$ in time period $t$

Minimum imports flowrate of gas form $i$ in zone $g$ in time period $t$

Big M parameter

Number of journeys that freight transport mode itr can do from zone $g$ to zone $g^{\prime}$

Operation time of freight transport per time period

Discount rate

Unit price of natural gas form $i$ in time period $t$ in the global market

Fixed capital cost of processing facility of type ipg

Variable capital cost of processing facility of type ipg, associated with plant capacity

Operating cost of processing facility of type ipg per unit of capacity

Variable operating cost of processing facility of type ipg

Capital cost of unprocessed gas per unit of maximum production capacity

Fixed operating cost of production of unprocessed natural gas

Variable operating cost of production of unprocessed natural gas

Fixed capital cost of storing natural gas of form $i$ in storage facility type is $f$ per storage facility built.

Variable capital cost of storing natural gas of form $i$ in storage facility type is $f$ Fixed operating cost of storing natural gas of form $i$ in storage facility type is $f$ Variable operating cost of storing natural gas of form $i$ in storage facility type isf

Fixed capital cost of pumping stations.

Fixed capital cost of transmission of natural gas of form $i$ per unit of flow capacity.

Fixed operating cost of transmission of natural gas of form $i$

Variable operating cost of transmission of natural gas of form $i$

Cost of buying a single unit of freight transport itr

Operating cost of freight transport itr per unit of transport available

Operating cost of freight transport itr per distance travelled

1 if zones can be linked directly by freight transporting gas of form $i, 0$ if not.

1 if zones can support processing infrastructure ipg, 0 if not.

1 if zones can support storage infrastructure is $f, 0$ if not.

Density of gas form $i$ 


\section{Introduction}

\subsection{The role of natural gas in Brazil's energy mix}

The World Energy Council (WEC) Trilemma Report [1] considers energy security, energy equity, and environmental sustainability as main features to define energy sustainability. Achieving high performance in all three dimensions requires to tackle of complex interactions and trade-offs between society, institutions and the environment. The report classifies the sustainability of an energy system by their ability to adapt and transform considering risks (e.g. the unattended consequences of the impact of rapid decarbonisation in the system energy security). Brazil, which is the world eighth largest energy user with a consumption of around $10.9 \mathrm{EJ} /$ year [2], is ranked $53^{\text {rd }}$ out of 125 countries in terms of its energy system sustainability [1]. In recent years, the country has been able to scale positions thanks to a decrease in energy exports and an increase in local oil and gas production [1].

In the last decade, the Brazilian energy system, especially the power sector, has experienced major changes. Although the power system still heavily relies on hydropower with a generation capacity of over $60 \%$, it has progressively become more vulnerable to blackouts due to delays in modernization of transmission lines, poor operating procedures, insufficient reactive power in regional subsystems, and an inadequate implementation in load shedding [3]. Although the extensive use of hydropower provides a low-carbon power sector, it is expected that the impacts of future climate change could stress the dynamics between the energy-water-food resources [1]. For instance, recent hydrological problems related to climate change such as droughts, floods and water scarcity generated by the natural dynamics of water and trade-offs between diverse water users (agriculture, industry, power) have affected the system reliability [4]. An important aspect to overcome water scarcity for future hydroelectricity planning is to appropriately understand the water-energy nexus of hydropower plants and its energy and water footprints; nevertheless, high uncertainties still exist regarding future water availability in the country [5].

As such, other energy sources such as wind, sugarcane bagasse, solar photovoltaic and natural gas power generation have been installed at higher rates [6]. Nowadays, wind installed capacity stands at $14.9 \mathrm{GW}$ or $9.1 \%$ of the total system capacity, bringing diverse socio-economic benefits [7]. Similarly, thermal-based power generation based on sugarcane bagasse is responsible for around $11.3 \mathrm{GW}$ or $6.9 \%$ of the total installed capacity, while natural gas stands at $13.3 \mathrm{GW}$. Biogas, a source that has been estimated with large power generation potentials due to organic waste availability, represents only $0.3 \%$ of the system installed capacity or $0.15 \mathrm{GW}$ [6]. According to Freitas et al. [8], currently the predominant biogas source for power generation in Brazil is urban solid waste $(96.8 \%)$, followed by animal waste (1.7\%) and agro-industrial waste (1.5\%). Lima et al. [9] provided a spatial distribution of landfill biogas production and power generation. The authors found a maximum landfill biogas installed capacity of $1.2 \mathrm{GW}$ by 2045 . Silva dos Santos et al. [10] projected a biogas power installed capacity potential between 4.5 and $6.9 \mathrm{GW}$, considering cattle manure as the largest untapped potential for biogas production (around $170 \mathrm{mcm} /$ day or $3.8 \mathrm{GW}$ ).

Although Brazil has one of the largest solar power generation potentials, currently photovoltaic (PV) panels only represent $1.3 \%$ of the total power system with an installed capacity of $2.1 \mathrm{GW}$, mostly located in the North-East region [6]. Soria et al. [11] argue that concentrated solar power (CSP) systems have the ability to provide flexibility to the region power system, supplying firm energy and 
dispatchable capacity, supporting a subsystem with high shares of intermittent wind energy. Carstens and Cunha [12] investigated the socio-technical potential of large scale PV installations in the country, finding that the most pressured needs are robust fiscal and financial incentives combined with clear long-term planning goals. Similarly, Garlet et al. [13] identified that the main barriers for large-scale PV implementation are high investment costs, access to poor quality technology, imports dependency, and a lack of incentives and policies. Nevertheless, the government projections anticipate solar power to reach an installed capacity of $9.6 \mathrm{GW}$ by 2026 [14].

Currently, natural gas has a participation of $12.9 \%$ in the Brazilian primary energy mix [15]. Figure 1 illustrates the historical daily average gas demand by sector as well as the historical gas-based power generation installed capacity.
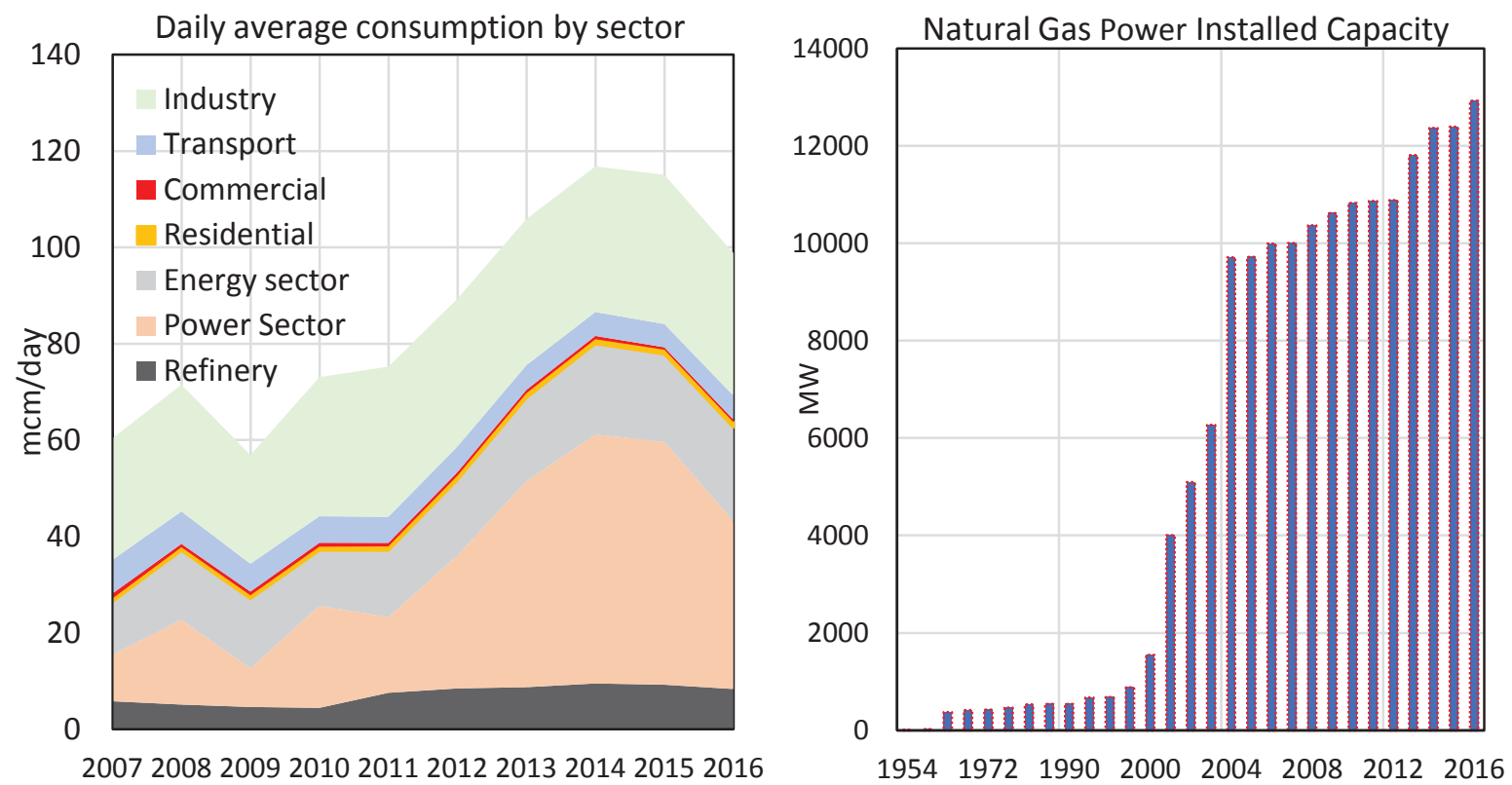

Figure 1 Brazil historical gas demand (left) and gas-fired power generation installed capacity (right). Sources: ANEEL [6], EPE [2].

Natural gas has gained importance due to its lower carbon emissions and competitive prices compared to alternative fossil-fuel energy sources [16]. It is estimated that Brazil has around 369 billion cubic meters $(\mathrm{bcm})$ of proven natural gas reserves, of which $82 \%$ is offshore [17]. In the last two decades, natural gas demand has seen a steady growth of $10.4 \%$ per year [18]. Between 1990 and 2013, natural gas reached 3 million users, covering 440 of the country 5,570 municipalities [19]. This increase has occurred mainly due to the following measures:

i. An increase in local production and imports from the Bolivian pipeline and investments in expanding the national pipeline network $(>15,000 \mathrm{~km})$.

ii. Privatisation of natural gas distribution companies and the expansion of the distribution network

iii. The thermoelectric priority programme (Decree No. 3,371/2000) introduced by the Ministry of Mines and Energy (MME).

iv. An increase in vehicle natural gas demand 
However, the low reliance of gas demand in certain sectors and regions is mainly due to the predominant role of hydroelectricity and sugarcane products, the underdeveloped gas infrastructure, the low demand for heating and the lack of investment and regulatory frameworks [20]. In the last decade, subsidies have been required for the deployment of natural gas projects, especially those related to the power [21] and fertiliser production [22]. Also, it was previously conceived that local resource development could have negative macroeconomic implications, as large economic and human resources would have been necessary for infrastructure development [23].

According to the National Agency of Petroleum, Natural Gas and Biofuels [17], local natural gas production in 2018 was $73.1 \mathrm{mcm} /$ day $(27.7 \mathrm{bcm} /$ year). In terms of imports, the country received on average $29.2 \mathrm{mcm} /$ day $(10.7 \mathrm{bcm} /$ year), with intakes from the Bolivian pipeline responsible for $83.5 \%$ of the total, while the rest was covered by liquefied natural gas (LNG) imports, mainly coming from Nigeria, the United Sates and Angola (Figure 2).

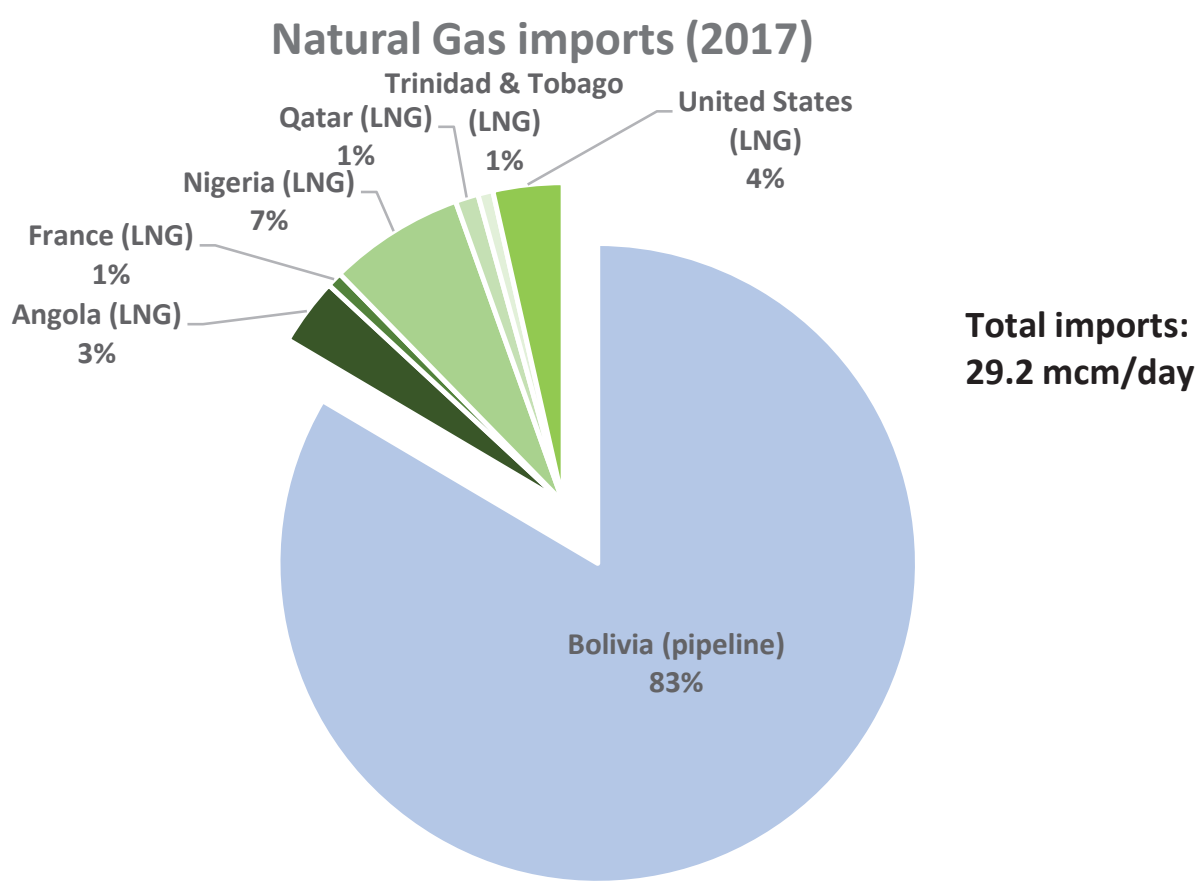

Figure 2 Brazil natural gas imports in 2017. Source: ANP [17]

Notwithstanding, natural gas is expected to grow considerably in the following decade [24]. According to the IEA [25], even under carbon constrained scenarios, natural gas demand would increase at least $25 \%$ by 2040 , mainly due to new gas-fired power plants that could act as support for the wide deployment of variable renewable energy. The Brazilian Energy Planning Company (EPE) [26], the entity responsible for forecasting long-term energy demand and organising auctions for power capacity and availability, projects that gas demand could grow to $108 \mathrm{mcm} /$ day $(39.4$ $\mathrm{bcm} /$ year) by 2026, with a maximum supply capacity of $120 \mathrm{mcm} /$ day $(43.8 \mathrm{bcm} /$ year). EPE also forecasts that the Northeast and Southeast grids will not have any infrastructure restrictions; however, the south grid, where the Bolivian-Brazilian pipeline lies, could have some infrastructure limitations due to higher gas demand growth rates in the region. 


\subsubsection{The GASBOL (Bolivia-Brazil) gas pipeline}

The construction of the Bolivia-Brazil pipeline (GASBOL) in 1998 represented a milestone in the expansion of the natural gas supply in Brazil, resulting in the integration of regional markets and national and international production areas. Initially, the 3,150 km pipeline (Figure 3) was established to supply around $8 \mathrm{mcm} /$ day. By mid 2000s, this was increased to $16 \mathrm{mcm} /$ day and finally to up to $30 \mathrm{mcm} /$ day, which is the pipeline current maximum capacity.

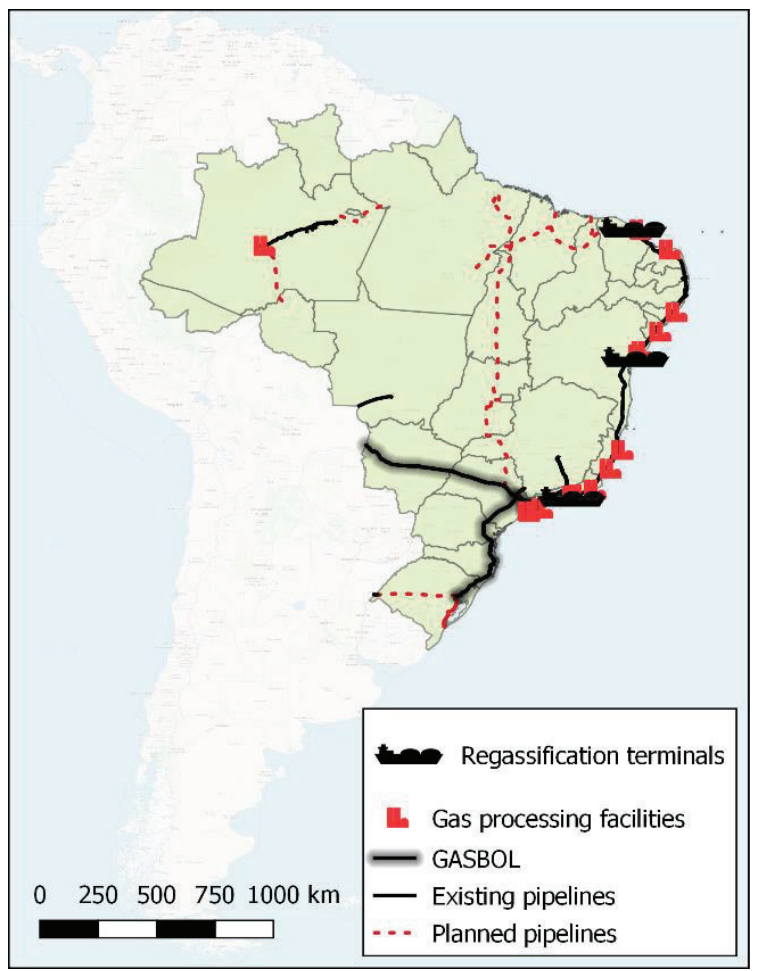

Figure 3 GASBOL pipeline location (shaded pipeline).

Just prior to the time of writing, PETROBRAS, motivated by increasing national energy security, decided to exercise the downward flexibility in its contract with Bolivia ( $80 \%$ monthly flexibility) to encourage local production [27]. In 2017, alleging lower industrial and power demand and higher domestic production, PETROBRAS announced that it was halving its offtake from Bolivia from 30 to $14.5 \mathrm{mcm} /$ day. Additionally, due to pre-salt natural gas production potential that could be commercialised, combined with current contract status between Bolivia and Brazil that is set to expire in 2019 [28], uncertainty exists regarding the future gas imports from Bolivia. The Petrobras 2030 Strategic Plan [29] projected that between 2020-2030, $24 \mathrm{mcm} /$ day would be under a take-orpay contract, and the remaining $6 \mathrm{mcm} /$ day would be interruptible. In their most recent projections [30], the company will seek to optimise the use of natural gas in the energy system, by seeking development of local markets.

\section{Existing literature}

\subsection{General gas modelling frameworks}

Energy models are powerful tools to forecast the impacts of energy policy, laws and programmes under different scenarios. Given the complexities of the natural gas supply chain, in particular the 
many possible pathways natural gas can take through it, planning and operation of the supply chain in order to meet growing demand needs to be carefully assessed. In this context, a wide range of gas infrastructure modelling studies can be found in the literature.

Lochner [31] presented a gas infrastructure linear optimisation model aimed at identifying bottlenecks of transport infrastructure in the European natural gas market. The model identified high market integration in Western Europe, while several bottleneck problems were found in Eastern Europe, with important implications for investment decisions in future infrastructure development. Dieckhöner et al. [32] presented a high-resolution European gas flow model to spatially and temporarily identify congestions in the transmission network under different infrastructure scenarios. Similarly to [31], the model also found a high level integration in Western Europe but with an important congestion area between Germany and Denmark hampering competition and limiting a complete physical market integration. The model suggests that storage and/or LNG regasification terminals would represent a more efficient investment instead of increasing pipeline transport capacity. Gillessen et al. [33] used a gas flow optimisation model (GASOPT) to understand how future energy systems would affect national energy security and its implications in long-term expansion planning of natural gas transmission networks. Using Germany as case study, the model found that although gas would act as a bridge to transition to a low-carbon economy, it is expected a lower gas demand in 2050 compared to baseline (2015) values, recommending to avoid any significant investment to expand the current transmission infrastructure and instead focusing on retrofitting it for hydrogen transportation.

Deane et al. [34] used the mixed-integer linear programming model 'PLEXOS' to develop an integrated gas and electricity model for the European Union. The model was based on a transportation algorithm to model gas flows within the region. To test the modelling framework, scenarios where interruptions of Russian and/or North African gas supply were analysed, focusing at understanding the disruption implications in the gas and power sectors. The assumed interruptions lead to the rise of both gas and electricity prices, highlighting the importance of the current gas network in the region power sector and energy security. Eser et al. [35] presented a natural gas optimisation model built in Pyomo [36], accounting for market behaviour of traders and operators. The framework was based on a two-step simulation approach: first, optimisation of gas sourcing was calculated based on Monte Carlo simulations for uncertain of gas prices; secondly, these outputs were used to simulate gas system operation, with the aim of optimising pipelines, compressors and storage devices using an hourly time resolution. The model was used to study the future impact of the new Russian gas pipeline (Nord Stream 2) as well as LNG imports on the gas supply security in the European Union.

Cafaro and Grossmann [37] developed a mixed integer non-linear program (MINLP) that models production and transmission using gradual refinement of linear approximations of the objective function. The objective function was based solely on maximising the net present value (NPV) to spatially determine different infrastructure, such as the number of wells drilled, gas processing plants, pipelines and compressors. Feijoo et al. [38] developed the North American Natural Gas Model (NANGAM), which is a partial equilibrium model that spatially models endogenous infrastructure expansion. As a case study, different gas pathways in Mexico under the new liberalised energy market were studied. Across all analysed scenarios, the model found feasible pathways of infrastructure expansion, which could have major implications on intraregional imports, especially from the USA. In a following study, Feijoo et al. [39] investigated the gas infrastructure 
development in the United States considering the implications of both domestic and cross-border (Canada and Mexico) socioeconomic effects. For this, a soft-link between GCAM-USA [40] and NANGAM was developed. The integrated model was able to spatially locate pipeline capacity expansion and under-utilisation risks, showing the importance of integrating different modelling approaches to provide robust scenarios for decision makers.

Shaikh et al. [41] modelled the future natural gas demand in China by using optimised nonlinear grey models. The model was able to capture nonlinear growth patterns of natural gas demand. Zhang et al. [42] used a multi-period multi-region optimisation model to study the implications of gas supply cost on future infrastructure development for China under different scenarios. The results illustrated the importance of unconventional gas production costs as well as import prices on the future development of gas infrastructure in the country.

For the specific case of South America, Chávez-Rodríguez et al. [43] used LEAP to project regional natural gas demand and understand the role of Bolivian imports within the subcontinent. The model used a bottom-up approach to simulate building, industrial, transportation and power sector gas demand. Later, Chávez-Rodríguez et al. [24] added the TIMES optimisation modelling framework to optimise natural gas supply and investigate energy systems dynamics in the southern Cone of Latin America (considering Argentina, Bolivia, Brazil, and Chile). This integrated model provided a better insight on future gas infrastructure considering interconnected markets. Patrício et al. [44] used a mathematical model to study the gradual replacement potential of natural gas by off-peak wind generated hydrogen in the state of Ceara, Brazil. The state of Ceara possess one of the greatest potentials for wind power generation, with a current installed capacity of $2.1 \mathrm{GW}$ [6].

Devlin et al. [45] highlighted the importance of gas infrastructure in power systems with high wind power generation. The authors used a multi-vector gas and power system analysis using Ireland as a case study. Findings suggests the high vulnerability of such power systems to gas infrastructure outages, resulting in almost a threefold increase in the system's marginal price. Qadrdan et al. [46] developed an optimisation model to investigate the operation of future gas networks under low carbon electricity and heat supply systems. The study found that the interrelation between gas networks and low carbon systems would affect the long-term operation of the gas networks, leading to lower annual gas flows. However, in a decarbonised power system that relies on large capacities of variable renewable energy (wind and solar), peak gas demand remains high, as gas-based power generation would be used at full capacity to compensate for variability from renewable systems. Using a similar model, Ameli et al. [47] investigated the implication of installing multi-directional compressor stations on the UK gas network and its impacts on the power supply security of the electricity sector, emphasising the importance of flexible optimal gas networks in future power systems with high shares of renewable energy sources, especially in dealing with wind power intermittency.

Arredondo-Ramírez et al. [48] presented a multi-period planning and infrastructure shale gas optimisation model based on disjunctive programming. The strength of the model was the possibility to account for optimal size of new infrastructure for diverse assets such as well exploitation, processing plants, and transmission and distribution pipelines. Börjesson and Ahlgren [49] used the partial equilibrium bottom-up optimisation model MARKAL to study the potential of biogas utilisation in the region of Västra Götaland, Sweden. The model presented a high resolution of biogas feedstocks and markets aiming at overcoming techno-economic barriers of large-scale 
deployment of biogas, especially for the transport and district heating sectors. Findings suggest that is economically feasible to build large regional pipeline grids, with co-distribution of biogas (upgraded to biomethane) and natural gas. The trade-off between temporal and spatial resolution in mixed-integer linear programming models has been discussed by Samsatli and Samsatli [50]. The authors' formulation presented a high temporal resolution involving hourly, daily, seasonal and yearly demand variations, suggesting its importance when modelling renewables and energy storage. Additionally, biomass modelling requires high spatial and seasonal resolution due to the yield and productivity variation. However, high resolution approaches could also cause the model to become intractable.

Research has also focused on gas infrastructure decarbonisation pathways using hydrogen as a fuel. For instance, Strachan et al. [51] utilised demand disaggregation through demand clusters centred on UK towns and cities. Supply was also disaggregated through splitting up of other renewable options (such as wind) depending on resource location, carbon storage options, and hydrogen and LNG terminals. Hydrogen infrastructure was disaggregated through three options: small scale production, gaseous pipelines and liquid delivery by tankers. Mixed integer programming was required to detail individual transmission and processing investments. Guillén-Gosálbez et al. [52] used a bi-criterion bi-level optimisation model for hydrogen supply chain design and planning. The multi-objective formulation accounted for environmental impacts expanding upon previous work utilising only time-invariant demand and single objective optimisation [53]. Hafsi et al. [54] developed a mathematical model to study the effects of upstream hydrogen injection on the natural gas pipeline network integrity. Finally, Reuß et al. [55] carried out a spatiotemporal hydrogen infrastructure expansion planning study in Germany using a technology-rich modular infrastructure chain model for well-to-tank and well-to-wheel analysis. The aim was to assess different infrastructure alternatives considering capital cost, carbon emissions and energy demand for hydrogen provision.

The aforementioned studies have highlighted the importance of energy systems and gas infrastructure models in identifying infrastructure decisions at a regional and international level. Nevertheless, due to modelling frameworks limitations, most of the presented studies have failed to provide robust interactions between the demand and supply sectors while delivering reasonable socio-economic and policy implications under a different set of scenarios. Notwithstanding, to the best of the authors' knowledge, a research gap exists regarding holistic natural gas supply chain modelling frameworks that deal with operation and expansion of available infrastructure to meet current and future demand. As changes in political environments (such as the case of Brazil) could greatly affect future gas dynamics at region level, integrated energy models are necessary to provide cost-effective infrastructure pathways under a different set of scenarios. Hence, the aim of this paper is twofold: i) describe a modelling framework that links a regional energy system model (MUSE-South_Brazil) with a novel gas supply chain infrastructure optimisation model (GINO), and ii) apply the model to the specific case of the southern states of Brazil, investigating the necessary critical gas infrastructure elements to cost-effectively cover future gas demand in medium and longterm periods (2015-2030 and 2030-2050).

This paper is organised as follows. First, the modelling approach which links MUSE-South_Brazil with the GINO optimisation model as well as the definition to the analysed scenarios is described. Next, the gas demand and infrastructure outputs for South Brazil is presented, followed by discussion and conclusions. 


\section{Materials and Methods}

\subsection{Modelling approach}

The proposed modelling framework is based on a soft-link between an energy system model (MUSESouth_Brazil) and a spatially resolved gas infrastructure optimisation model (GINO). This integrated modelling framework has been used to forecast regional gas demand (based on socio-economic parameters and technology competition) and to provide cost-effective gas supply chain infrastructure from 2015 through 2050. A simple schematic of the integration and main data flow between models is illustrated in Figure 4.

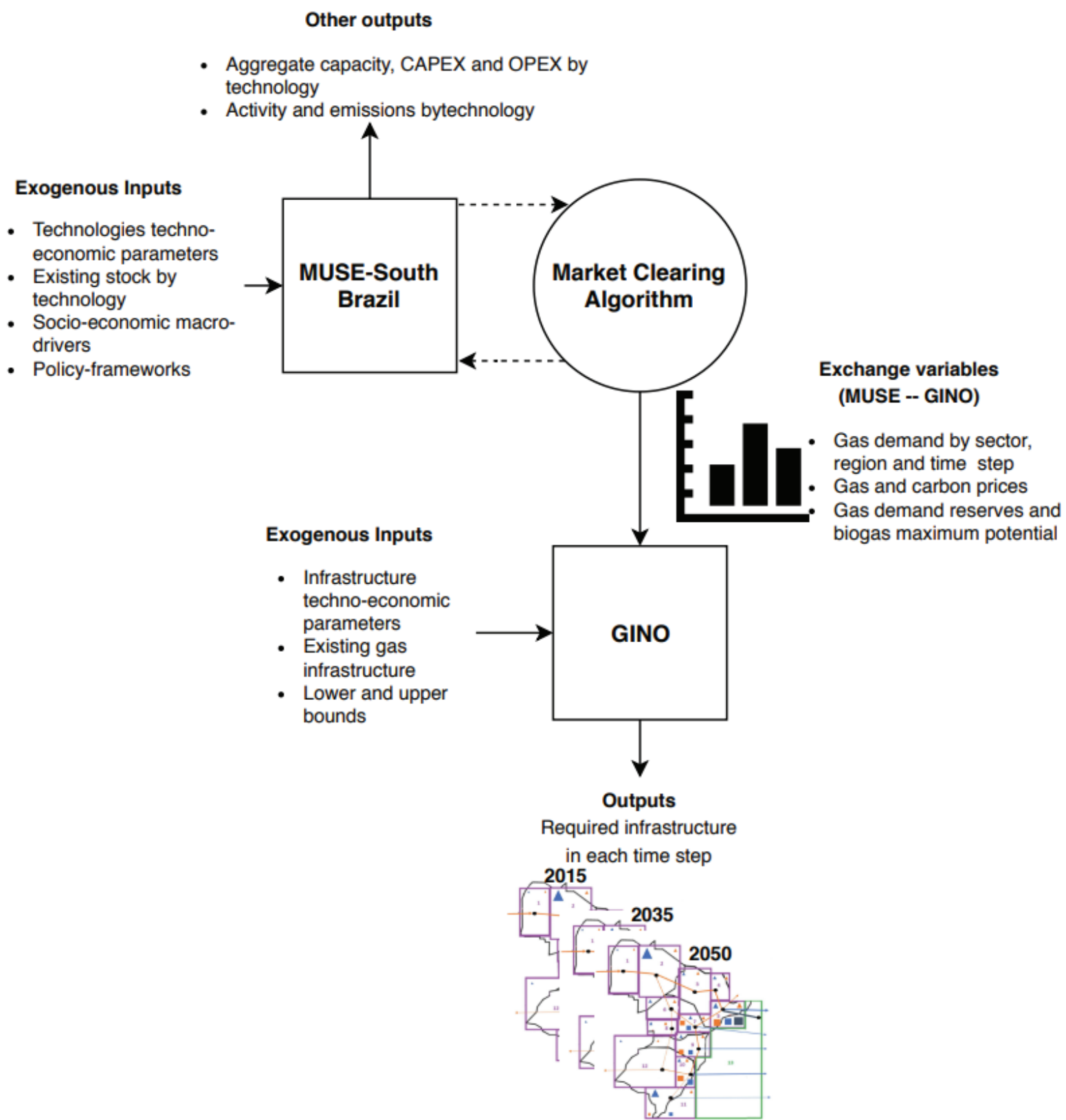

Figure 4 Integrated modelling framework between MUSE-South_Brazil and GINO. 
The selected case study is based on the south stream of Brazil's gas infrastructure. This gas stream passes through five states: i) Mato Grosso do Sul, ii) Sao Paulo, iii) Parana iv) Santa Catarina and v) Rio Grande do Sul (Figure 5). The five-state region was subdivided into twelve zones representing major urban areas, allowing for infrastructure to be built in and connect different zones in different time periods (Figure 5). An additional area (grid \#13) has been added representing the Pre-Salt region (Santos basin). As illustrated, natural gas imports could come from Bolivia (entering grid \#1), north-Argentina (entering grid \#12) and offshore gas reserves from the Campos basin or LNG imports entering grids with coastal areas (grids \# 5, 7, 9, 10, 12). National trade is considered with the south-east grid from Rio de Janeiro (entering either through grid \#4 and \#5). Additionally, it is assumed that grid \#3 and \#6 are able to produce onshore gas, while biogas production can be produced in every onshore region. A summary of the grids, availability for imports and production, and grids distance can be found in Appendix A.

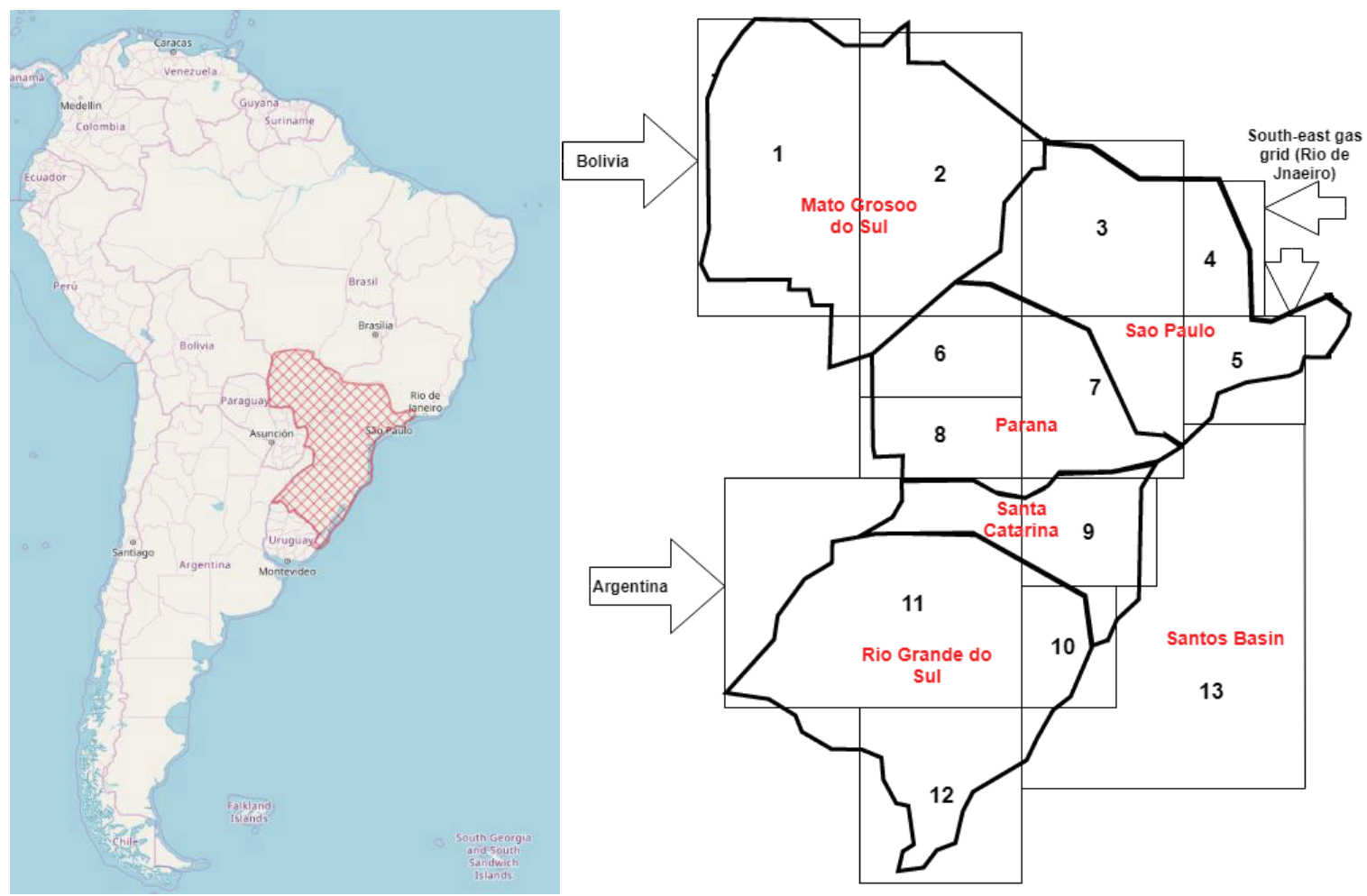

Figure 5 Case study: Brazilian natural gas south grid composed by five states located in the southern part of the country.

\subsection{MUSE-South_Brazil}

To simulate future gas demand in the region, the paper presents the integration of an energy systems model (MUSE-South_Brazil) with a gas infrastructure model (GINO). This integration is powerful as the investment in the gas infrastructure in GINO is informed by the endogenous gas demand as obtained from MUSE-South_Brazil. MUSE-South_Brazil has been developed from the MUSE modelling environment [56] which is developed in the Python programming language [36]. The model is a partial-equilibrium simulation model using a bottom-up technology-rich approach of the complete energy system (supply, transformation and demand), where each sector is modelled accordingly to its specific characteristics. The model uses a limited foresight approach to forecast future energy commodity prices [57], resulting in a more realistic representation of stakeholders' decision-making process for investing into new energy technologies. MUSE includes all the energy 
sectors, demand, conversion and supply, which are interfaced using a market equilibrium algorithm or market clearing algorithm (MCA), responsible for the information flow between sectors, iterating between sector modules until price and quantity of each energy commodity converge. To represent the future state of the sector, the model selects technologies based on capital and operational costs, technology efficiency and environmental impacts. The model produces a time series of energy, land demand and related emissions to meet the projected energy service demand. MUSE responds to parameters such as Gross Domestic Product (GDP), population growth and household income, as well as carbon and fuel prices.

Additionally, MUSE applies an agent-based modelling approach in the residential and commercial sector [58]. Also, the agriculture and land use sector module is capable of simulating future agricultural mechanisation diffusion, providing realistic bioenergy potentials and land use demands [59]. As the model simulates relationships among the sectors by means of the MCA, this allows to simulate the availability of specific resources. For example, to account for the maximum biogas potential within a specific region; the calculated agricultural residues and dedicated energy crops availability is sent to the refinery sector, where the investment and operation of anaerobic digestion (AD) processes is simulated. In Appendix B, the generic MUSE modelling framework is illustrated and further explained.

MUSE-South_Brazil has been previously used to explore the role of reforestation and land use in achieving national carbon mitigation targets [60]. For this study, regional macroeconomic parameters have been obtained from Brazil's institutions such as EPE [15] and IBGE [61] data.

As a second simulation step, natural gas projections by sector and by region from MUSE are passed on to GINO, from 2015 to 2050 in 5-year periods. In GINO, demand constraints are imposed such that the model meets the required demand in each time-step and region. The details of GINO are explained in the following section.

\subsection{Gas Supply Chain Infrastructure Optimisation Model (GINO)}

\subsubsection{General Gas Supply Chain Model description}

The novel Gas INfrastructure Optimisation model (GINO) has been developed for this study. GINO is a time-dependent, multi-node, mixed-integer linear program (MILP) developed in GAMS [62] aiming at optimising operation and investment in gas supply chain infrastructure. Three forms of natural gas are characterised in GINO: unprocessed, processed, and liquefied natural gas (LNG). A schematic of the supply chain stages considered is illustrated in Figure 6. The model describes six components of the supply chain: production, processing, transport (via pipeline or freight), storage, international trade (imports and exports), and consumption. The model considers local natural gas production as the extraction of unprocessed gas from underground reservoirs (mainly from the Santos Basin). The processing stage refers to the conversion between forms of natural gas (from unprocessed natural gas to processed natural gas), while liquefaction converts processed natural gas to LNG, and regasification converts LNG to processed natural gas. Biomethane production is also considered as a processing stage. Biomethane is considered equivalent to processed natural gas and can be blended into natural gas in limited quantities. Finally, the model also considers two storage alternatives: above ground and underground storage facilities. 


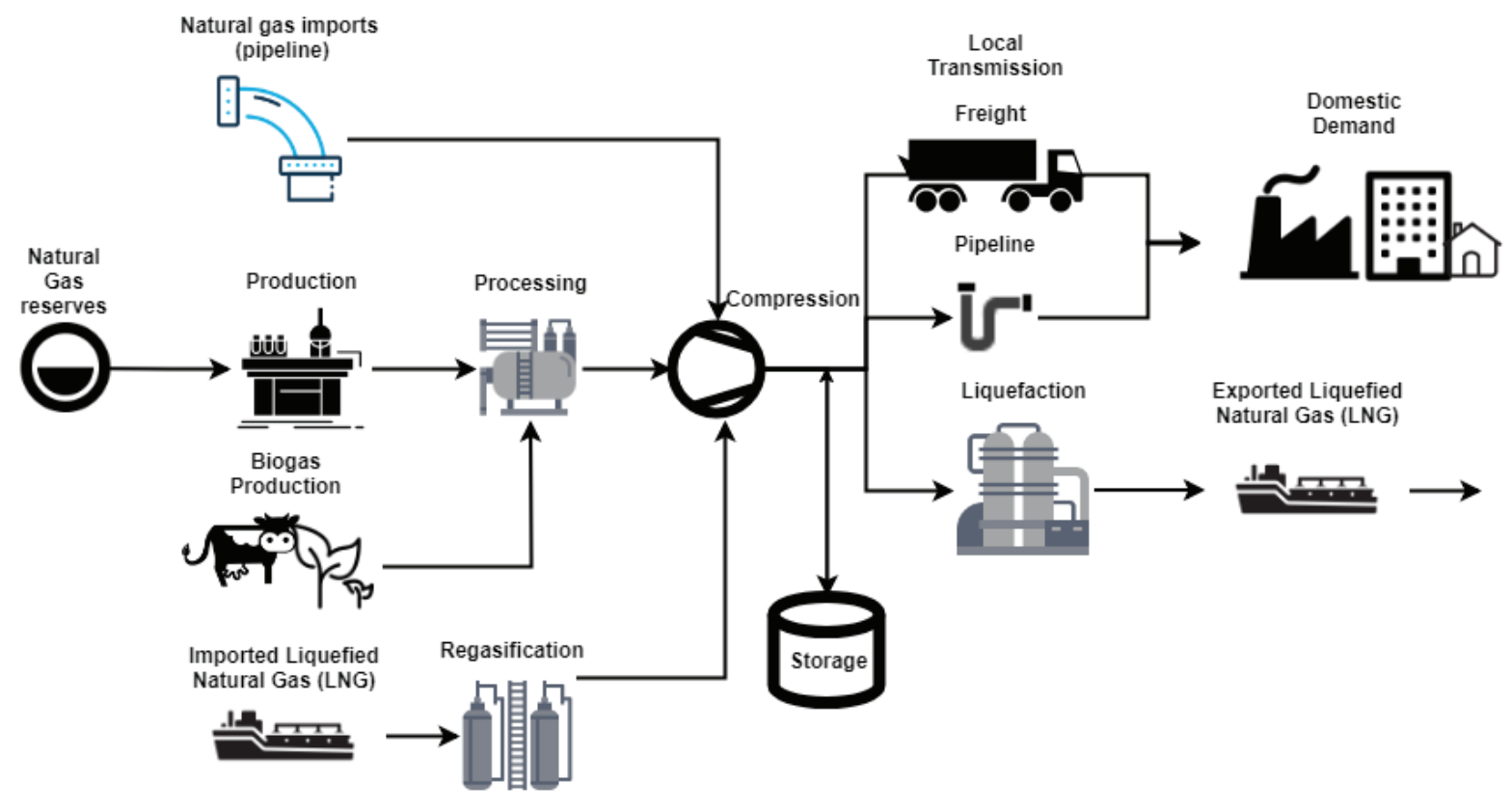

Figure 6 Supply chain gas infrastructure schematic.

The following subsection describes the main elements of the optimisation formulation and main constraints. Appendix $\mathrm{C}$ shows the detailed full model formulation.

\subsubsection{Gas model mathematical formulation}

\subsubsection{Objective function}

The objective function minimises the total discounted cost for the whole system, as shown in Equation (1).

$$
\min _{\text {s.t. }} T D C=\sum_{t} \frac{T C_{t}}{(1+r)^{t-1}}
$$

Where $T C_{t}$ is the total system cost in each time period as described in Equation (2).

$$
\begin{aligned}
T C_{t}=P R C C_{t}+ & T C C_{t}+T R C C_{t}+P G C C_{t}+S C C_{t} \\
& +\left(P_{R O C}+\text { TOC }_{t}+\text { TROC }_{t}+P G O C_{t}+S O C_{t}+I C_{t}-E R_{t}\right) \\
& \cdot \text { Duration }_{t}
\end{aligned}
$$

\subsubsection{Production}

Production rate of natural gas is bounded by a big-M constraint to ensure there can only be production if the site is operational, as shown in Equation (3). Production rate is also bounded by available reserves in the production facility, as shown in Equation (4). Equation (5) links the available reserves with how much was produced in the last time period. 


$$
A P_{\text {gipr } t} \leq m \cdot V R_{\text {gipr } t} \quad \forall g, \text { ipr }, t
$$

$$
V R_{\text {g ipr } t}=V R_{\text {gipr } t-1-A P_{\text {ipr } t-1} \cdot \text { Duration }_{t} \quad \forall g, \text { ipr }, t}
$$

\subsubsection{Transmission}

Natural gas can be transported between zones via pipelines or via road freight. This section describes the main equations for transmission via pipelines. Equation (6) states that there can only be a flow of gas type $i$ between zone $g$ and zone $g^{\prime}$ if there is a compressor station installed in zone $g$. Equation (7) only allows gas to flow in one direction through each pipeline.

$$
\begin{array}{cc}
Y 3_{g g^{\prime} i t} \leq Y 2_{g t} & \forall g, g^{\prime}, i, t \\
Y 3_{g g^{\prime} i t}+Y 3_{g^{\prime} g i t} \leq 1 & \forall g, g^{\prime}, i, t
\end{array}
$$

Equation (8) couples the continuous variable for flow between zones to the binary variable that describes whether there is a flow of gas $i$ between two zones. The total gas flow is then bounded by the total pipeline capacity between zones in Equation (9). Equation (10) states that the number of pipelines for gas type $i$ in a given time period is equal to the number of pipes in the previous time period, plus the ones that were added.

$$
\begin{array}{lr}
\frac{Y 3_{g g^{\prime} i t}}{M 1} \leq Q P_{g g^{\prime} i t} \leq Y 3_{g g^{\prime} i t} \cdot \mathrm{M} 1 & \forall g, g^{\prime}, i, t \\
Q P_{g g^{\prime} i t} \leq N P_{g g^{\prime} i t} \cdot C a p P_{i} & \forall g, g^{\prime}, i, t \\
N P_{g g^{\prime} i t}=N P_{g g^{\prime} i t-1}-N P A_{g g^{\prime} i t} & \forall g, g^{\prime}, i, t
\end{array}
$$

\subsubsection{Freight transport}

This section presents equations that describe gas transport through freight. Equation (11) describes the total flow rate transported by each freight transport mode as the volume of gas across all freight units, over the duration of the time period. Equation (12) bounds the total number of transport units available for transporting gas from each zone, while Equation (13) allows for purchasing additional transport units.

$$
Q F_{g g^{\prime} \text { i itrt }}=U 1_{g g^{\prime} i} \cdot \frac{C T J_{g g^{\prime} i \text { itr } t} \cdot N J_{g g^{\prime} i t r}}{\text { Duration } t} \forall g, g^{\prime}, i, i t r, t
$$




$$
0 \leq \sum_{g^{\prime}, i} \frac{\operatorname{CTJ}_{g g^{\prime} i \text { itr } t}}{\operatorname{CapTr}_{\text {itr }}} \leq A N T_{g i t r t} \quad \forall g, i t r, t
$$

$$
A N T_{\text {gitr } t}=A N T_{\text {gitr } t-1}+N T P_{g_{\text {itr }}} \quad \forall g, i t r, t \geq 2
$$

\subsubsection{Processing}

As mentioned before processing facilities can convert gas forms into different gas forms. Processing facilities can be built in each zone, and processing rates are constrained as shown in Equation (14). Equation (15) states that maximum value for processing rate can be expanded. The total expanded capacity is constrained by minimum and maximum numbers of production facilities that can be installed in each time period, as shown in Equation (16).

$$
\begin{aligned}
& P G_{g_{\text {ipg }}} \leq C P G_{\text {gipg } t} \quad \forall g, i p g, t \\
& C P G_{g \text { ipg } t}=C P G_{g i p g t-1}+C E P G_{g i p g t} \quad \forall g, i p g, t \geq 2 \\
& M \text { inCapP } G_{\text {ipg }} \cdot N P G_{\text {gipg } t} \leq C E P G_{\text {gipg } t} \\
& \leq M a x C a p P G_{\text {ipg }} \cdot N P G_{\text {gipg } t} \quad \forall g, i t r, t
\end{aligned}
$$

\subsubsection{Storage}

Gas forms can be stored between time periods, as the balance shows in Equation (17). Equation (18) ensures that in each storage facility gas is either being stored or removed over each time period. In Equation (19) the stored volume in each facility is bounded by the maximum capacity of the facility, and by a buffer capacity. Finally, Equation (20) ensures that a fraction of the demand for subsequent time period is stored, to allow for demand shocks, considering the densities of different gas forms.

$$
\begin{gathered}
V S_{g i \text { isf } t}=V S_{g i \text { isf } t-1}+\left(Q \text { SIN }_{g i \text { isf } t-1}-\text { QSOUT }_{g i \text { isf } t-1}\right) \\
\cdot \text { Duration }_{t} \forall g, i, \text { isf }_{, t}
\end{gathered}
$$




\subsubsection{Material balances}

For each form of gas, Equations (21), (22), and (23) show the material balances into and out from each zone, for each time period.

$$
\begin{aligned}
& \sum_{g^{\prime}} Q P_{g^{\prime} g N G t}+\sum_{g^{\prime}, i t r} Q F_{g^{\prime} g N G i t r t}+Q I_{g N G t}- \\
& \sum_{g^{\prime}} Q P_{g g^{\prime} N G t}-\sum_{g^{\prime}, i t r} Q F_{g g^{\prime} N G i t r t}-Q E_{g N G t}+ \\
& P G R_{g N G P t}+P G R_{g R G t}-\frac{\rho_{L N G}}{\rho_{N G}} \cdot P G R_{g L F t}+
\end{aligned}
$$

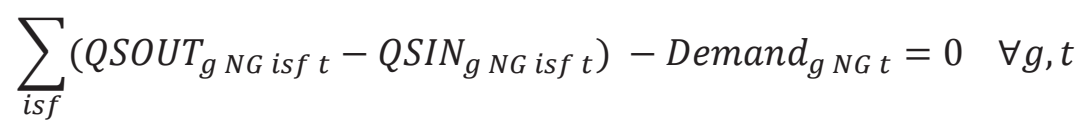

$$
\begin{aligned}
& \sum_{g^{\prime}} Q P_{g^{\prime} g L N G t}+\sum_{g^{\prime}, i t r} Q F_{g^{\prime} g L N G i t r t}+Q I_{g L N G t}- \\
& \sum_{g^{\prime}} Q P_{g g^{\prime} L N G t}-\sum_{g^{\prime}, i t r} Q F_{g g^{\prime} L N G i t r t}-Q E_{g L N G t}+ \\
& P G R_{g L F t}-\frac{\rho_{N G}}{\rho_{L N G}} \cdot P G R_{g R G}+ \\
& \sum_{\text {isf }}\left(Q_{S O U T} \text { LNG isf } t-\operatorname{QSIN}_{g \text { LNG isf } t}\right)-\text { Demand }_{g L N G t}=0 \quad \forall g, t \\
& \sum_{g^{\prime}} Q P_{g^{\prime} g U P t}-\sum_{g^{\prime}} Q P_{g v g^{\prime} U P t}+\sum_{i p r} A P_{g i p r t}-\frac{\rho_{N G}}{\rho_{U P}} \cdot P G R_{g N G P t}=0 \quad \forall g, t
\end{aligned}
$$

Finally, Equation (24) limits biogas production to the maximum allowable volume fraction of biogas in gas streams.

$$
P G R_{g B G P t} \leq \frac{f b g}{1-f b g} \cdot P G R_{g N G P t} \quad \forall g, t
$$

\subsection{Scenario definition}

Service demand projections across the sectors are based on the Shared Socioeconomic Pathways Two (SSP2) [63]. Although the SSP2 qualitative narrative describes a middle-of-the-road development in mitigation and adaptation, leading to a projected temperature increase of $4{ }^{\circ} \mathrm{C}$ by the end of the century, Fricko et al. [63] shows that the added value of the SSP2 marker 
implementation is that offers a useful starting point to explore carbon mitigation solutions aiming at limiting temperature increase below $2{ }^{\circ} \mathrm{C}$, due to the implementation of robust climate-oriented policies. To quantitatively translate the narrative into the specific case of Brazil, the following main assumptions by 2050 in the energy and agriculture and land use systems have been made based on the storyline elements presented by [63]: for instance, it is assumed that Brazil would reach medium electrification, expecting a maximum of $50 \%$ road transportation to be covered by electric vehicles, combined with maximum annual electrification rates of about $1.5 \%$ and $0.5 \%$ in the building and industrial sectors respectively. For the case of carbon capture and storage (CCS) technologies, cost reductions between $10 \%$ and $40 \%$ are expected. In terms of land use and agriculture, deforestation rates are kept below $1 \%$ per year until reaching positive natural vegetation regeneration by 2050, combined with moderate yield pasture efficiency growth (from an average of 1 cattle head per hectare in 2015 to 1.7 by 2050). Macroeconomic data suggest that by 2050, Brazil will have a per capita income of about $\$ 22,617$ and a population of 232 million inhabitants. For the specific case of the analysed five-state region, per capita income is expected to be higher than the national average at around $\$ 29,611$ (2005 USD) with a population of 83 million inhabitants.

MUSE-South_Brazil projects service demands under a $2^{\circ} \mathrm{C}$ scenario based on the carbon budget presented by Rochedo et al. [64]. The authors estimated the country budget by analysing the outputs from different global integrated assessment models. Furthermore, the authors considered three different environmental governance scenarios (strong, intermediate, and weak) allocating different shares of the carbon budget to land use and the energy system. In this study, we have considered their 'Strong Environmental Governance' scenario, which allocates $40 \%$ of the budget to land use and agriculture and $60 \%$ to the energy system. This scenario has similar assumptions to the SSP2 regarding deforestation control policies and an increase intensification of agricultural activity.

For the specific case of regional natural gas demand, a single demand has been calculated. The demand for natural gas will depend on the simulated technological share across different sectors. Various new laws and regulations are likely to affect regional gas dynamics in coming years. For instance, in 2017, the 'Pre-salt Law regulation' changed the criteria for investments and operations in the Brazilian pre-salt areas, revoking the obligation for PETROBRAS to be the sole operator and to hold a minimum stake of $30 \%$ in exploration and production consortiums. Additionally, the Gas to Grow Programme (Gás para Crescer) (Draft Law 6,407/2013) is a major government plan that is expected to be implemented in the upcoming years. Thus, three different scenarios for gas infrastructure are explored assuming different imports projections based on future governmental plans:

- Scenario 1. Considers that current Bolivian gas imports rates remain constant throughout the analysed period (2015-2050), while national intakes from the southeast grid also remain constant. The Argentinian pipeline is expanded in 2035 (from $3 \mathrm{mcm} /$ day to $7 \mathrm{mcm} /$ day), and expanded fivefold by 2040, reaching a maximum inflow of $15 \mathrm{mcm} /$ day. This assumes that the 'Vaca Muerta' basin in Central Argentina will be in full operation by that time.

- Scenario 2. Considers the reduction of Bolivian Gas imports by a third (from 30 to 20 $\mathrm{mcm} /$ day according to Petrobras and EPE projections) during the next decade (2020-2030). Later, imports are reduced to half of the base year's current capacity, with maximum imports of $15 \mathrm{mcm} /$ day. On the other hand, the southeast grid intakes remain constant (10 $\mathrm{mcm} /$ day), while the Argentinian pipeline expands its capacity sooner than in Scenario 1 . It is assumed that in 2025 it reaches $11 \mathrm{mcm} /$ day, and a maximum flow of $15 \mathrm{mcm} /$ day by 2040 . 
- Scenario 3. Considers a case where Bolivian imports suffer a gradual reduction until being removed from the market. First, capacity gets reduced by a third in $2025(20 \mathrm{mcm} /$ day $)$, and then by two thirds in 2030 (10 mcm/day). Finally, after 2030, import flows from Bolivia are completely stopped. In this case, the maximum imports from the southeast branch are expanded by one third in 2030 (reaching $18 \mathrm{mcm} /$ day), while the Argentinian pipeline follows the same infrastructure expansion as in Scenario 2.

A summary of the maximum assumed imports for each scenario are illustrated in Figure 7.
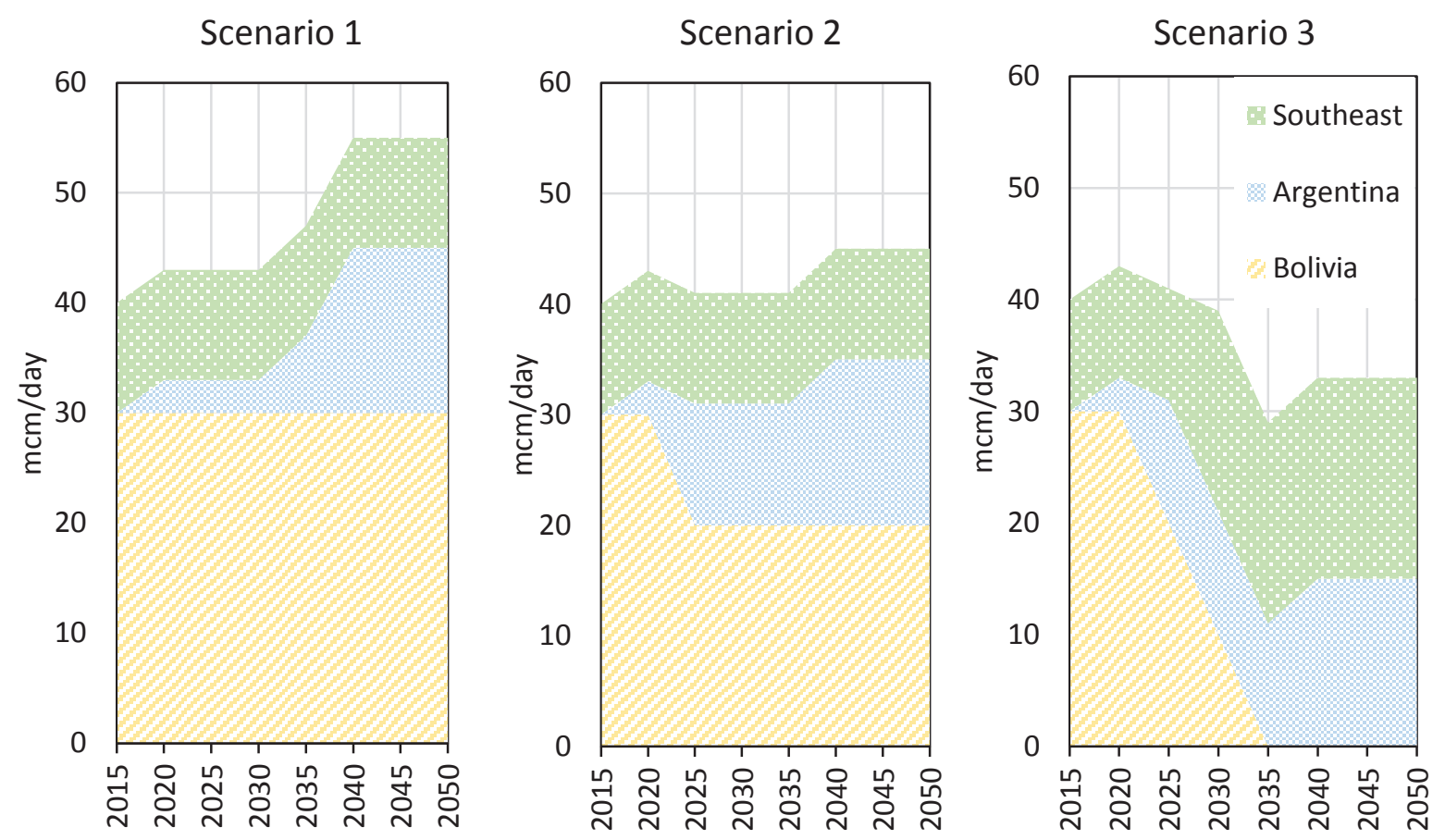

Figure 7 Maximum natural gas import flow rates assumed from Bolivia, Argentina and the Southeast grid.

Additionally, the model considers imports from new LNG terminals, with a maximum regional possible installed capacity of $20 \mathrm{mcm} /$ day, restricted to the grids with coastal areas. Finally, for intakes from the pre-salt area (grid \#13), the model considers a reserve value of $49 \mathrm{bcm}$ for the base year [17] (and up to $106 \mathrm{bcm}$ if probable reserves are considered). Currently, daily production in the region after internal consumption, flaring, and reinjection, stands at around $14.8 \mathrm{mcm} /$ day $(5.4$ bcm/year) [17].

\subsection{Model calibration and validation}

For the calibration and validation of MUSE South_Brazil and GINO, the model follows a split sample approach. In the MUSE model, the calibration implies that data for technological installed capacity are collected for the assumed base year (2010) in order to match the sectoral energy consumption, sectoral emissions, and land use demand to IEA [65] and FAO [66] databases. 2010 has been selected as a base year because of the existence and reliability of national and local government data for all the sectors $[2,61,65]$ as well as being a year without significant political, economic or environmental circumstances. Nevertheless, some uncertainties could arise due to lack of detailed sectoral data by state. In this case, based on national values, sectoral GDP share per state has been used to characterise certain subsectors, especially in the industrial sector (cement, steel, paper). In 
the GINO model, gas reserves have been calibrated to the Rystad upstream database [67], while pipelines gas flows and capacities have been calibrated using government data [17].

The model was validated performing an integrated MUSE-South_Brazil and GINO simulation between 2010 and 2015. The simulated results in terms of 2015 energy demand and sectoral emissions were compared against the IEA database. Considering an aggregation of all the sectors, a normalised error $(\varepsilon)$ of $3.4 \%$ for energy consumption and $-0.10 \%$ for emissions have been found. Regarding the specific case of natural gas demand in the region, a normalised error $(\varepsilon)$ of $-2.8 \%$ was found.

In 2015 , the five-state region demanded around $39 \mathrm{mcm} /$ day. The baseline gas infrastructure is illustrated in Figure 8 . It shows the main input flows from the Bolivian pipeline $(25-30 \mathrm{mcm} /$ day $)$, the southeast stream $(6 \mathrm{mcm} / \mathrm{day})$ and the unprocessed gas coming from the pre-salt region (14.7 $\mathrm{mcm} /$ day). If surplus gas exists, this is transferred to the southeast region. Grid \#5 (Sao Paulo, Campinas, Santos area) demands around $25 \mathrm{mcm} /$ day (more than 60\%), and is where most of the gas infrastructure exists, such as processing $(23 \mathrm{mcm} /$ day $)$ and large storage $(396 \mathrm{mcm})$ facilities. On the other hand, grids \#6, 8, 11 and 12 are the only ones not connected to the transmission grid due to their low demand (a combined of $3 \mathrm{mcm} /$ day or $7.1 \%$ of the total regional demand). However, the low gas demand is mainly covered by tanker trucks. In total, $5.5 \mathrm{mcm} /$ day are transported by trucks throughout the entire region.

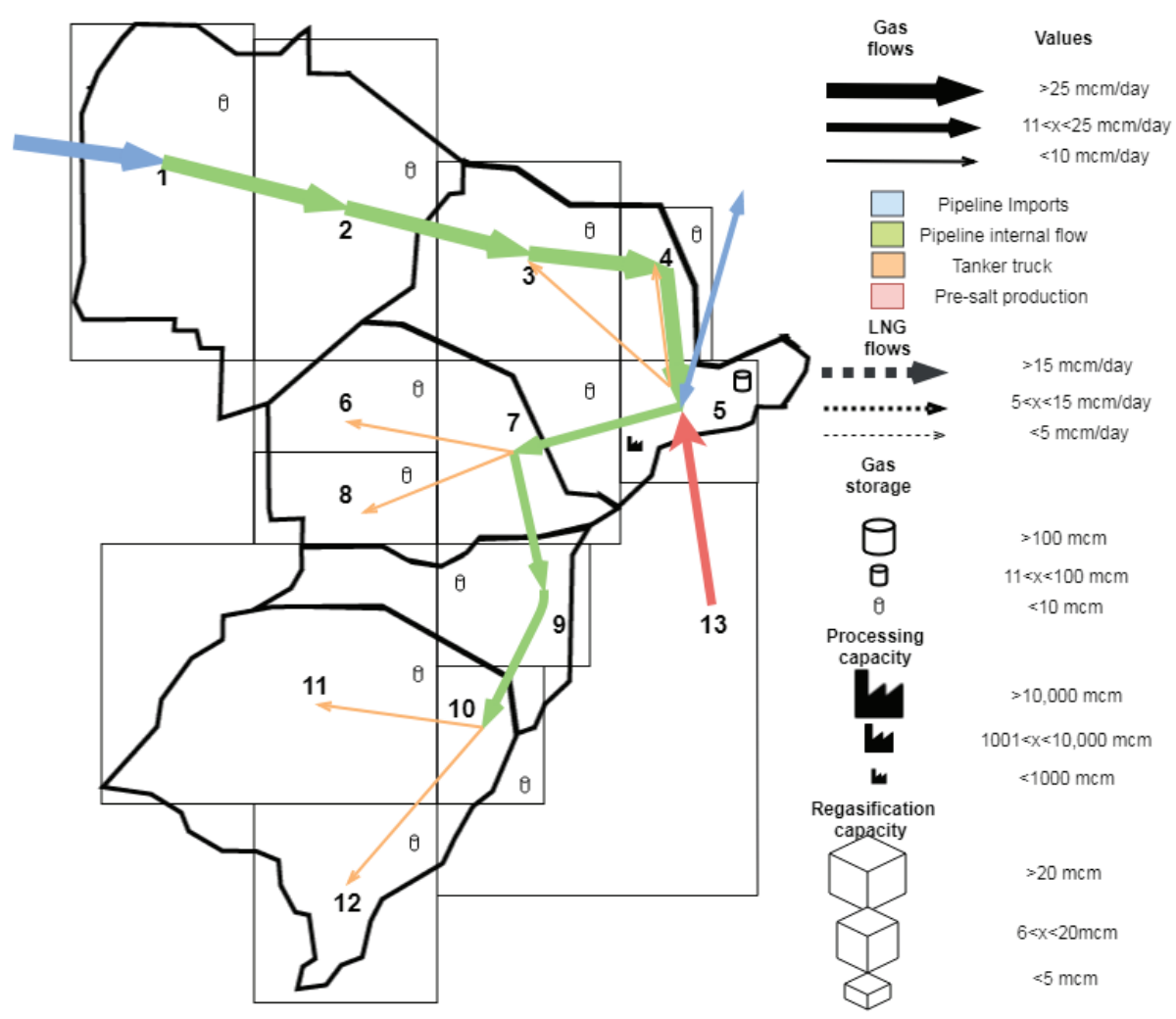

Figure 8 Base year infrastructure in the gas south grid states in Brazil 


\section{Results and Discussion}

\subsection{Gas demand forecast}

Figure 9 shows the natural gas consumption outputs for the five-state region, considering exclusively the demand sector. Results show an expected average annual growth rate of $2.1 \%$ between 2015 and 2030, and 1.9\% between 2030 and 2050, increasing from $30.8 \mathrm{mcm} /$ day $(11.2 \mathrm{bcm} /$ year) to 61.2 $\mathrm{mcm} /$ day $(22.3 \mathrm{bcm} /$ year $)$. Most of the increase would be driven by the industry sector $(+19.8$ $\mathrm{mcm} /$ day), responsible for $65 \%$ of the increase, followed by residential $(+9.0 \mathrm{mcm} /$ day or $30 \%)$, transport $(1.5 \mathrm{mcm} /$ day or $5 \%)$, and commercial $(-0.02 \mathrm{mcm} /$ day, $-0.1 \%)$. Most of the new gas demand in the industry sector is expected to come from the steel and fertiliser subsectors. For the residential sector, the increase is due to the installation of gas-based cooking and water heating replacing LPG-based equipment. On the other hand, the small increase in transport is due to the sector's electrification in later years, while the commercial sector expects a wide range installation of heat pumps to cover both cooling demand and water heating requirements.

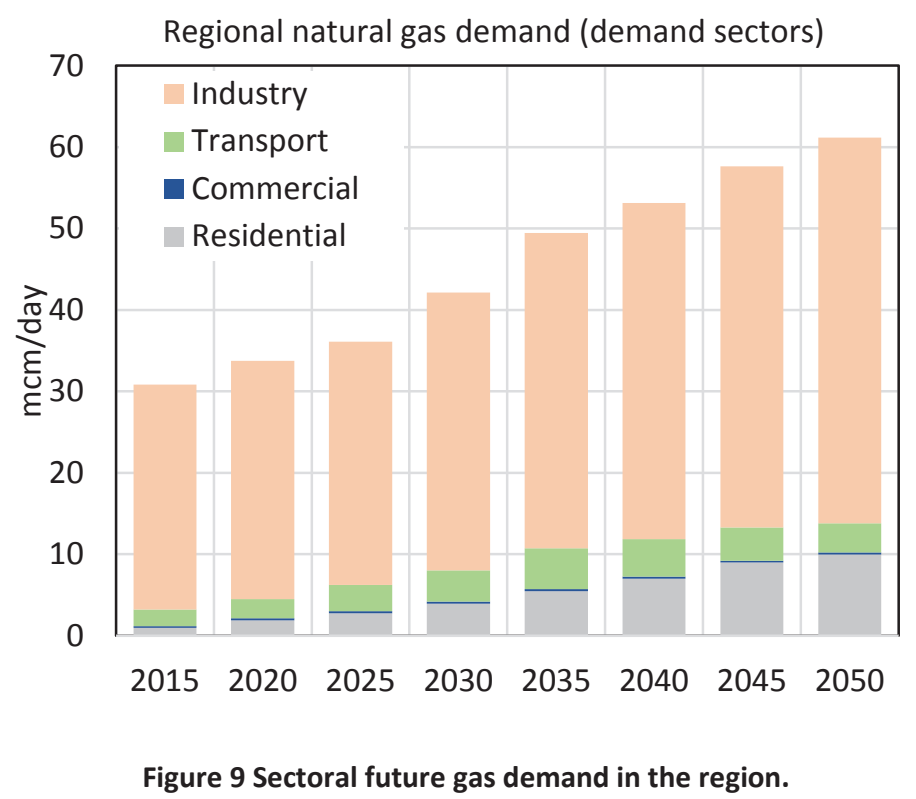

Figure 10 shows future regional electricity demand by sector, which influences the gas demand in the power generation. Electricity demand is expected to grow at an average annual rate of $2.5 \%$, increasing from $214 \mathrm{TWh} /$ year to $473 \mathrm{TWh} /$ year by 2050. Figure 10 also illustrates the modelling outputs regarding the expected power installed capacity by technology. Regarding the specific case of gas, by 2030, a maximum addition of $6 \mathrm{GW}$ of new gas-based combined cycle plants can be expected, and by 2050 , total gas capacity could reach $21 \mathrm{GW}$. These plants are expected to cover the increase in electricity peak demand in the region, covering the system's base load. However, hydropower and biomass would still represent the most important power sources in the system. 

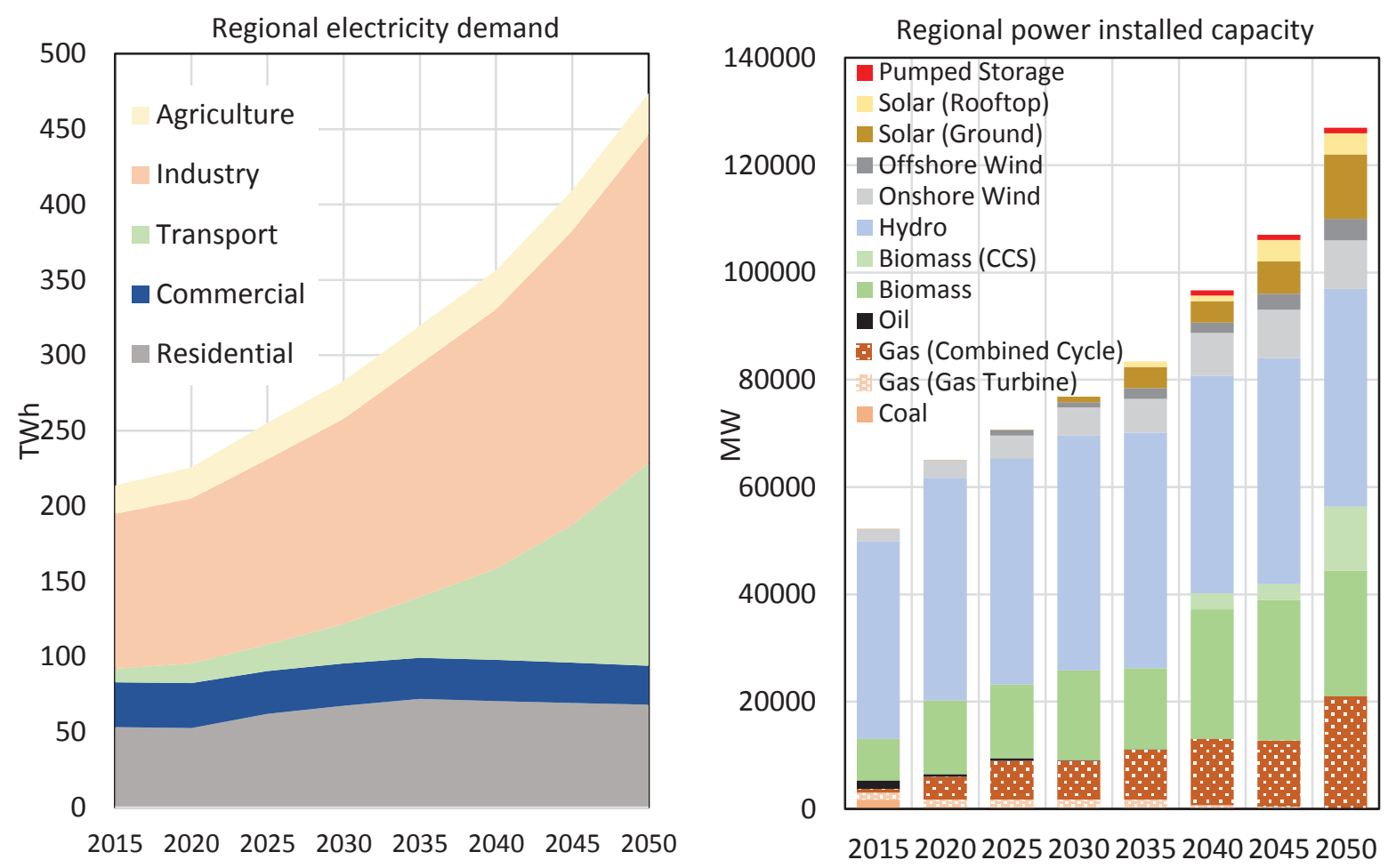

Figure 10 Sectoral electricity demand (left) and power installed capacity (right) for the analysed region.

Finally, Figure 11 shows the total regional gas demand considering both the power and demand sectors. The model forecasts a total increase of $65.6 \mathrm{mcm} /$ day by 2050 , reaching average consumption rates of $104.3 \mathrm{mcm} /$ day. This value is similar to the current national natural gas demand of $105 \mathrm{mcm} /$ day [17]. Also, the demand in each modelled grid (subregions) is illustrated. Outputs suggest that grid \#5 would be the main consumer, with average values of $67 \mathrm{mcm} /$ day or $64.4 \%$ of the total regional demand. This high demand corresponds to the cities of Sao Paulo, Santos, Campinas and Sao Jose dos Campos, which have the larger population share and important industrial activity. This is followed by grid \#7 (Curitiba and Ponta Grossa) and Grid \#10 (Porto Alegre and Caixas do Sul), with a combined gas consumption of $15 \mathrm{mcm} /$ day. These values have been used as inputs in to the GINO model to explore the required future gas infrastructure in the region. 
Regional natural gas demand (demand and power sectors)

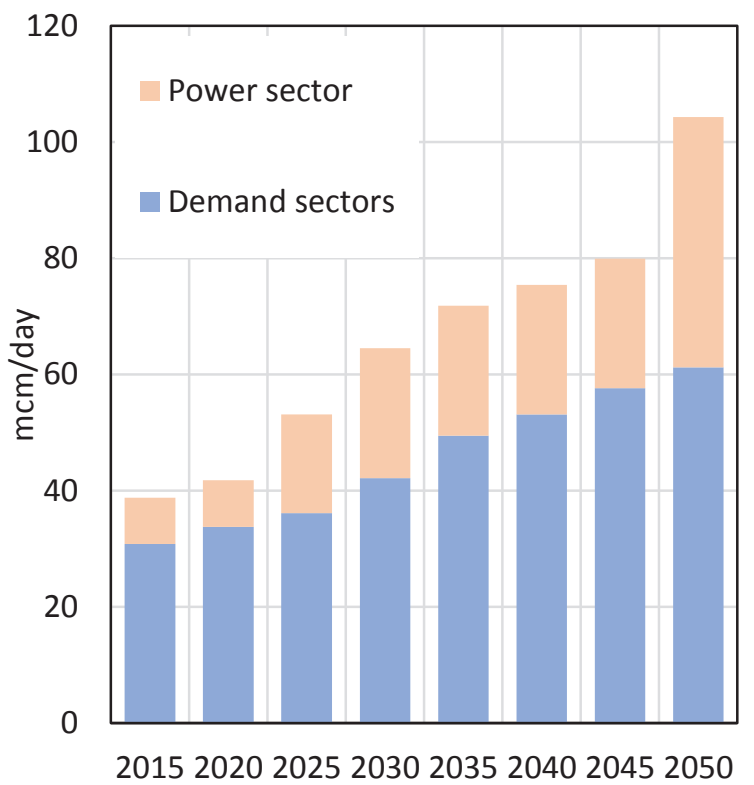

Natural gas demand by grids

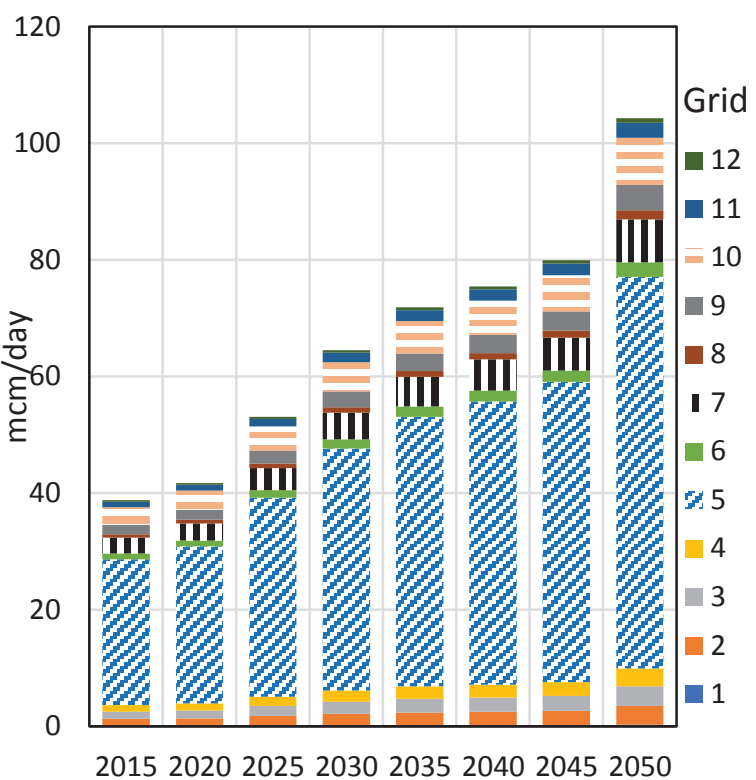

Figure 11 Total regional natural gas demand (left) and natural gas demand by grid zone (right).

\subsection{Natural gas infrastructure}

Figure 12 illustrates the required future infrastructure in the region for Scenario 1 . As in this scenario the main assumption is that Bolivian imports are maintained as per the time of writing (around 30 $\mathrm{mcm} /$ day) to cover the future demand, additional imports would be required from Argentina (15 $\mathrm{mcm} /$ day) combined with consistent imports in the order of $12 \mathrm{mcm} /$ day from the southeast stream. Also, the pre-salt production would have to increase from $15 \mathrm{mcm} /$ day to $21 \mathrm{mcm} /$ day. The model builds pipelines throughout the subregions which lacked infrastructure previously (Grids \#6, $8,11,12)$, aiming at reducing transportation costs. The construction of this part of the pipeline network is designed such that all grid zones are connected to either a source of production or import site. Brazil is currently considering construction of a pipeline between what has been denoted as grids $\# 10$ and $\# 12$, which is confirmed in the model as a logical endeavour. However, the main infrastructure addition to the system is due to the extra $31 \mathrm{mcm} /$ day from LNG imports, requiring new large regasification terminals across the coastal regions. Most of the LNG would enter through grid \#5 (13.8 mcm/day) and grid \#10 $(9.1 \mathrm{mcm} /$ day), represented by Santos (SP) and the coast near to Porto Allege (RS), respectively. Finally, as there would be a surplus of around $5 \mathrm{mcm} /$ day, the model suggests that instead of transferring the surplus to the southeast grid, it should be exported as LNG due to price competitiveness. 


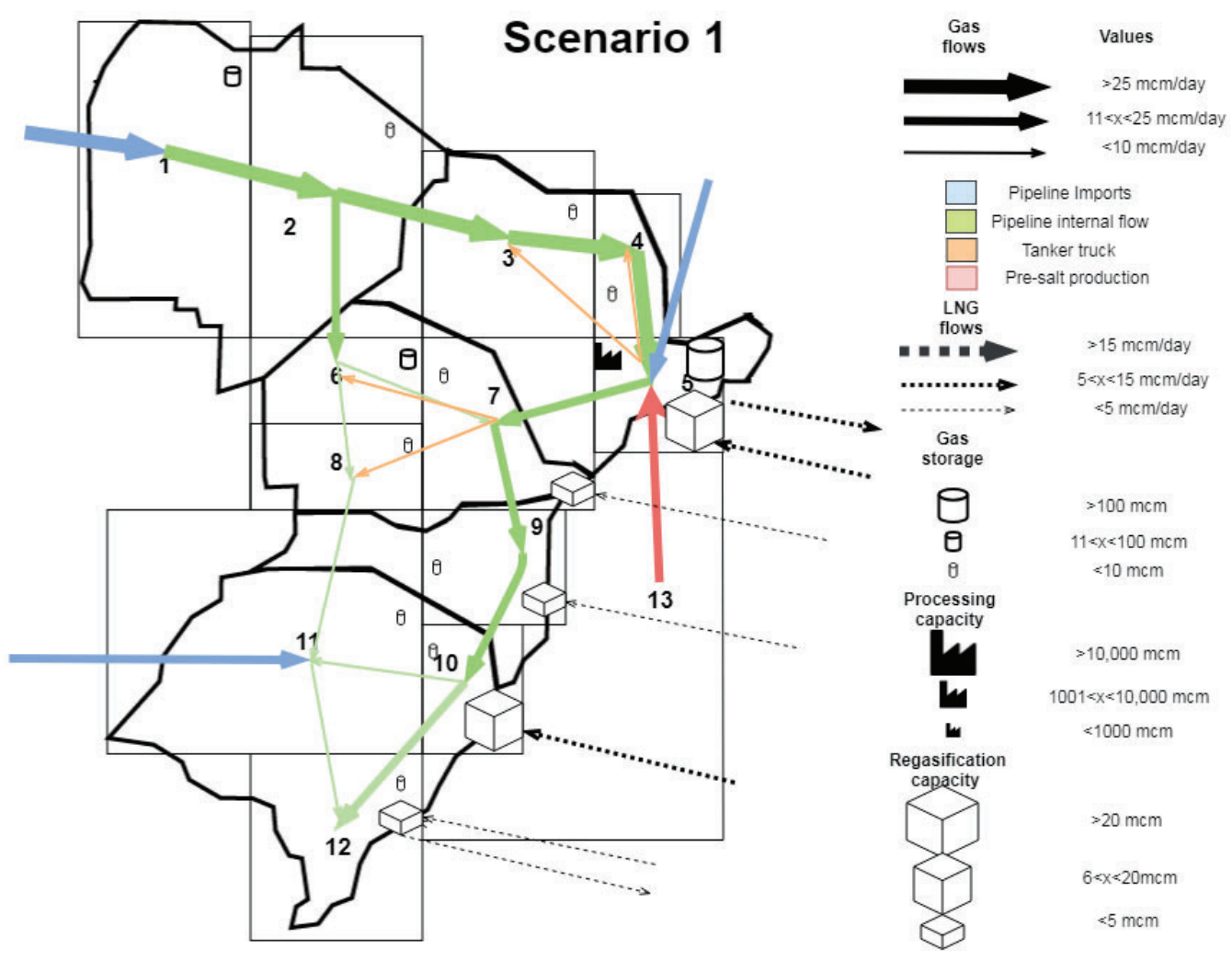

Figure 12 Future infrastructure (2050) in the gas south grid states in Brazil for Scenario 1

Figure 13 shows the infrastructure for Scenario 2, where Bolivian imports are halved by 2050. The main differences with Scenario 2 are the need to increase pre-salt production to $25.6 \mathrm{mcm} /$ day, while LNG imports reach $43.7 \mathrm{mcm} /$ day. Therefore, larger regasification terminals would be required throughout the region. For instance, grid \#5 would require a regasification capacity of around 29.6 $\mathrm{mcm} /$ day, while grid \#12, represented by the coastal city of Rio Grande (RS), would require a terminal for $3.5 \mathrm{mcm} /$ day. This scenario has an increase in total costs by $15 \%$ compared to Scenario 1.

Finally, Figure 14 illustrates the required infrastructure for Scenario 3, where Bolivian imports are completely halted. The model suggests a larger import participation form the southeast grid, reaching $18 \mathrm{mcm} /$ day, putting major pressure on the rest of the Brazilian gas system. Additionally, the pre-salt region would have to increase its production to $27.5 \mathrm{mcm} /$ day, requiring larger gas processing facilities. Moreover, LNG imports would reach a maximum of $48.8 \mathrm{mcm} /$ day, thus requiring large regasification terminals in all coastal regions but \#7. However, the main difference in the infrastructure is the gas flow direction adjustment at the GASBOL pipeline, as the gas demand for grids \# 1, 2, 3, and 4 would be covered by gas flow coming from grid \#5 and not from Bolivia. Also, the pipeline connection between grid 6 and 2 would not be required due to low gas demand among the regions. The total cost of this scenario is approximately $36 \%$ and $18 \%$ more than for Scenario 1 and Scenario 2, respectively. 


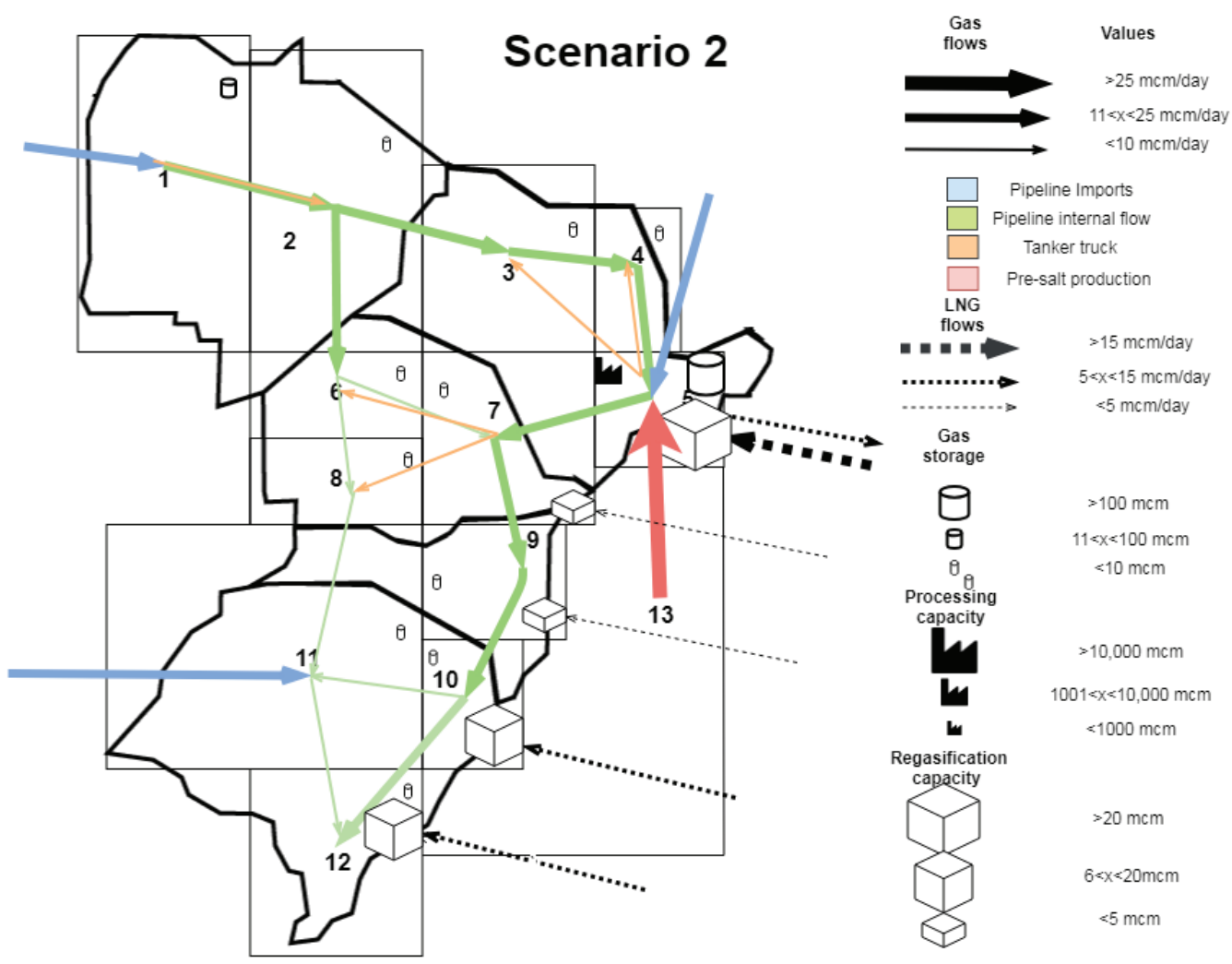

Figure 13 Future infrastructure (2050) in the gas south grid states in Brazil for Scenario 2
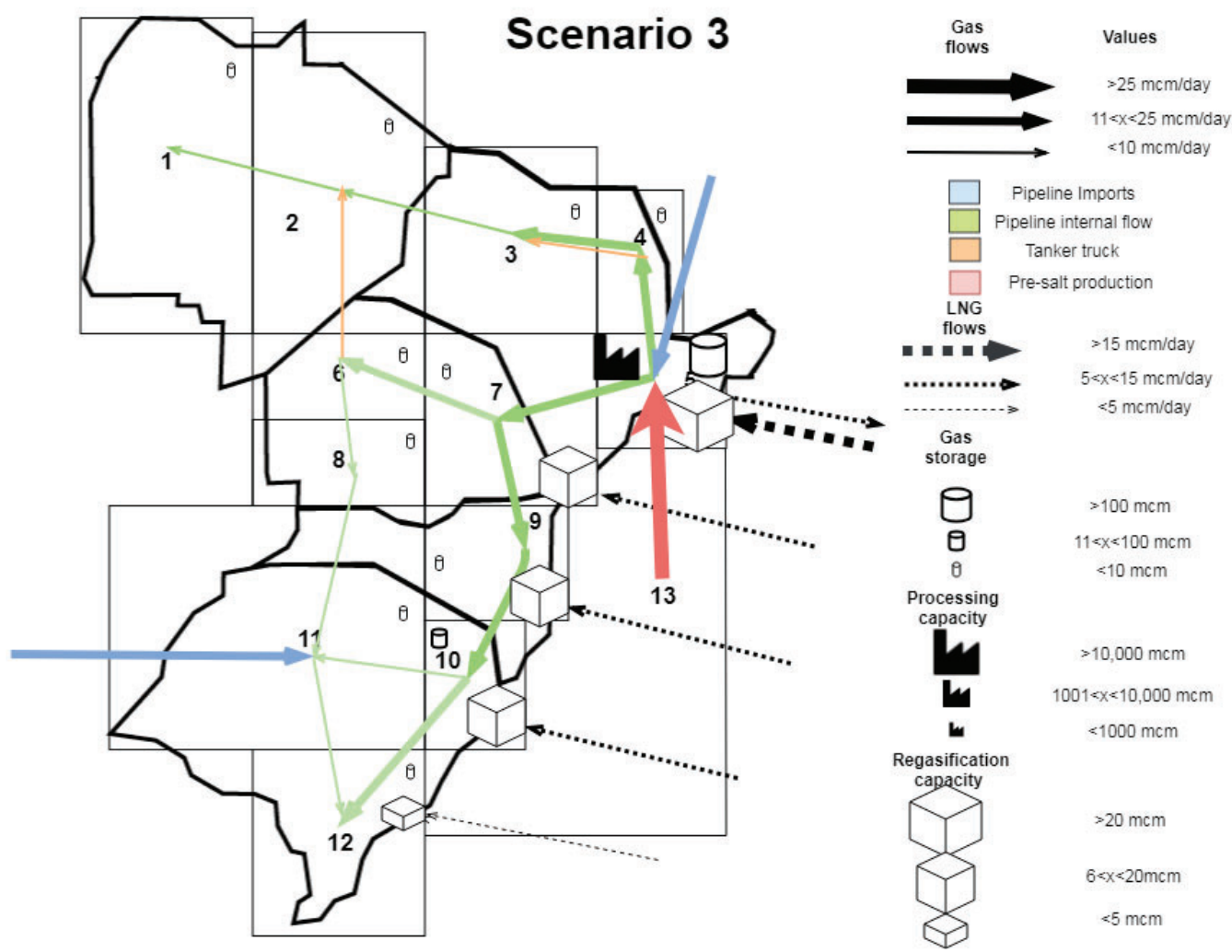

Figure 14 Future infrastructure (2050) in the gas south grid states in Brazil for Scenario 3 


\subsection{Discussion}

The uncertainty generated by the ongoing contract negotiations between Brazil and Bolivia for the renewal of gas imports has motivated this study. The framework developed has investigated costeffective infrastructure pathways under different assumptions for the southern states in Brazil. This application demonstrated the flexibility of the model with regards to varying input data, such as existing trade agreements and infrastructure. The model produces logical results in terms of the location of infrastructure.

The use of an integrated assessment model has provided the opportunity to understand complex dynamics between the different gas producing and consuming sectors. This study has confirmed how additionally to direct gas consumption in the demand sector (especially in the industry and residential sector), electrification in transport would put pressure on a power system, mainly dominated by hydro generation. As a matter of fact, these additional electricity demand derives is supplied by the installation of gas power plants.

Regardless of the analysed gas supply scenario, it is envisioned that the region would diversify natural gas sources (Figure 15). Both, LNG imports and pre-salt production would have to increase their market share. However, for the country not to diminish its energy security, it needs to be cautious in depending too much on LNG imports, as shown in Scenario 2 and 3. The rearrangement of flows obtained in Scenario 3 is also a major infrastructure decision that needs to be carefully considered. Results suggest that Bolivian gas needs to remain as part of the gas supply to lower future infrastructure cost and provide operational flexibility.

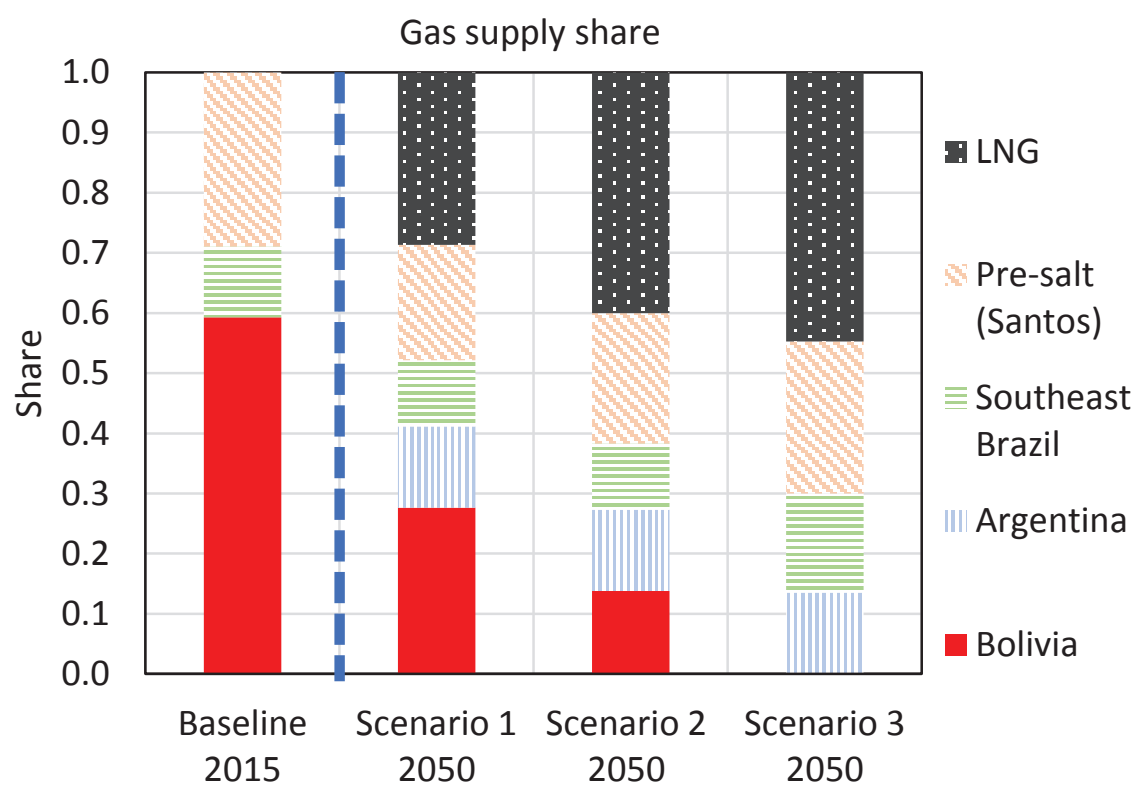

Figure 15 Gas supply share comparison

Additionally, the results from the South Brazil case study highlighted an important trade-off between long-term energy security and short-term revenue from exports. Due to the implementation of a time horizon and no incentive to maintain reserves, the model produces as much as possible in order to maximise export revenue. 
The role of programmes such as the Gas to Grow (Gas para Crescer) will increase the competitiveness of natural gas within the national energy matrix. These outputs are critical to provide support for planning and evaluation at different stages in the supply chain, providing decision makers and other government bodies with tools to evaluate options for capacity expansion in the region.

\section{Conclusion}

The importance of gas in Brazil and the uncertainty in supply sources bring challenges for future energy security. When planning, robust tools are necessary. This study coupled a regional energy system model with a novel gas infrastructure optimisation model, investigating different infrastructure pathways assuming different import rates from the Bolivian pipeline. The focus was to explore the potential new infrastructure required in the region, considering future gas demand under a carbon constrained energy system.

The results from this study suggest that by 2050, gas consumption in the demand sectors of the fivestate region would increase two-fold, reaching $60 \mathrm{mcm} /$ day. The industrial sector, mainly driven by steel and fertiliser production, would be responsible for $65 \%$ of the new regional gas demand, followed by the residential sector $(30 \%)$ due to large-scale installation of gas-based cooking and water heating equipment. Gas demand for power generation would add an extra $40 \mathrm{mcm} /$ day, driven by the increase of electricity demand of $221 \%$, growing from 214 TWh to 478 TWh. Due to decommissioning and increasing demand, by 2050 the region would require $21 \mathrm{GW}$ of new installed gas capacity.

At present, although the Bolivia-Brazil gas pipeline (GASBOL) is an important infrastructure asset, due to constraints capacities and prospects for future gas demand in the region, a diversification in gas suppliers is expected to maintain the system's cost as low as possible while ensuring long-term energy security and even short-term revenues from potential exports. However, as demonstrated by the analysed scenarios, keeping current levels of Bolivian gas intakes could minimise the total system's cost as much as $36 \%$, providing greater operational flexibility compared to a scenario where Bolivian gas intakes are completely ceased. Depending on the scenario, infrastructure pathways suggest a total deployment of a gas transmission network with new additions of regasification terminals across the coast, as imports between $31.2 \mathrm{mcm} /$ day (Scenario 1) and $48.8 \mathrm{mcm} /$ day (Scenario 3) are obtained.

Nevertheless, a careful planning is necessary to avoid stranded gas infrastructure assets as it could complicate the achievement of future carbon mitigation targets in the national energy system. In this sense, the utilisation of integrated models, such as the one presented in this study, could provide crucial information for decision and policy makers to conduct robust analysis and support comprehensive natural gas infrastructure planning and policies.

For future work, the model will be expanded to account for updated values of the natural gas reserves regarding production rates in the context of depletion, as well as more sources of biomethane production. Additionally, an improved technoeconomic assessment of gas assets is needed as well as a more granular temporal characterisation to account for seasonal fluctuation of different energy sources and its impact on gas supply. Future work includes a multi-objective optimisation with the additional objective of minimising greenhouse gas emissions. Particularly, the 
model will be expanded to include fugitive emissions from the gas supply chain, which are a significant contributor to global warming. A more comprehensive modelling of the global trade environment could also be beneficial, to respond to the actions of the region of interest. For example, to reflect the consequences of flooding the global market.

\section{Acknowledgments}

The authors would like to acknowledge the Sustainable Gas Institute, Imperial College London and the Natural Environment Research Council (NERC) under the Newton Fund (NERC reference: NE/N018656/1) for funding this work.

\section{References}

[1] WEC. World Energy Trilemma Report 2018. In: WYMAN. WECipwO, editor. United Kingdom 2018.

[2] EPE. National Energy Balance 2016 (Balanço Energético Nacional 2016). In: Energética EdP, editor. Rio de Janeiro, Brazil Ministry of Mines and Energy (Ministerio de Minas e Energia ); 2017.

[3] Veloza OP, Santamaria F. Analysis of major blackouts from 2003 to 2015: Classification of incidents and review of main causes. The Electricity Journal. 2016;29:42-9.

[4] Semertzidis T, Spataru C, Bleischwitz R. Cross-sectional integration of the water-energy nexus in Brazil. Journal of Sustainable Development of Energy, Water and Environment Systems. 2018;6:114-28.

[5] Semertzidis T, Spataru C, Bleischwitz R. The nexus: Estimation of water consumption for hydropower in Brazil. Journal of Sustainable Development of Energy, Water and Environment Systems. 2019;7:122-38.

[6] ANEEL. Capacidade de Geração do Brasil (Brazil's Generation Capacity). In: http://www2.aneel.gov.br/aplicacoes/capacidadebrasil/capacidadebrasil.cfm, editor. Brazil 2018.

[7] Simas M, Pacca S. Socio-economic benefits of wind power in Brazil. Journal of Sustainable Development of Energy, Water and Environment Systems. 2013;1:27-40.

[8] Freitas FF, De Souza SS, Ferreira LRA, Otto RB, Alessio FJ, De Souza SNM, et al. The Brazilian market of distributed biogas generation: Overview, technological development and case study. Renewable and Sustainable Energy Reviews. 2019;101:146-57.

[9] Lima RM, Santos AHM, Pereira CRS, Flauzino BK, Pereira ACOS, Nogueira FJH, et al. Spatially distributed potential of landfill biogas production and electric power generation in Brazil. Waste Management. 2018;74:323-34.

[10] Silva dos Santos IF, Braz Vieira ND, de Nóbrega LGB, Barros RM, Tiago Filho GL. Assessment of potential biogas production from multiple organic wastes in Brazil: Impact on energy generation, use, and emissions abatement. Resources, Conservation and Recycling. 2018;131:54-63.

[11] Soria R, Lucena AFP, Tomaschek J, Fichter T, Haasz T, Szklo A, et al. Modelling concentrated solar power (CSP) in the Brazilian energy system: A soft-linked model coupling approach. Energy. 2016;116:265-80.

[12] Carstens DDdS, Cunha SKd. Challenges and opportunities for the growth of solar photovoltaic energy in Brazil. Energy Policy. 2019;125:396-404.

[13] Garlet TB, Ribeiro JLD, de Souza Savian F, Mairesse Siluk JC. Paths and barriers to the diffusion of distributed generation of photovoltaic energy in southern Brazil. Renewable and Sustainable Energy Reviews. 2019;111:157-69. 
[14] EPE. Ten Year Energy Expansion Plan 2026 (Plano Decenal de Expansão de Energia

2026). In: Energética EdP, editor. Rio de Janeiro, Brazil Ministry of Mines and Energy (Ministerio de Minas e Energia); 2017. p. 264.

[15] EPE. Balanço Energético Nacional 2017. In: Energética EdP, editor. Rio de Janeiro, Brazil Ministerio de Minas e Energia; 2018.

[16] Kotchen MJ, Mansur ET. Correspondence: Reassessing the contribution of natural gas to US CO2 emission reductions since 2007. Nature Communications. 2016;7:10648.

[17] ANP. Dados estatísticos. In: Agência Nacional do Petróleo GNeB, editor.2019.

[18] Gomes I. Brazil: Country of the future or has its time come for natural gas? In: Studies TOIfE, editor.2014.

[19] Francisco G. Brazil prepares to privatize local natural gas distribution companies. export.gov: U.S. Commercial Service of the U.S. Department of Commerce 2017.

[20] Campos AF, da Silva NF, Pereira MG, Vasconcelos Freitas MA. A review of Brazilian natural gas industry: Challenges and strategies. Renewable and Sustainable Energy Reviews. 2017;75:1207-16.

[21] Gorini de Oliveira R, de Moraes Marreco J. Natural gas power generation in Brazil: New window of opportunity? Energy Policy. 2006;34:2361-72.

[22] dos Santos PC, Szklo AS. Urea imports in Brazil: The increasing demand pressure from the biofuels industry and the role of domestic natural gas for the country's urea production growth. Journal of Natural Gas Science and Engineering. 2016;29:188-200.

[23] Goldemberg J, Schaeffer R, Szklo A, Lucchesi R. Oil and natural gas prospects in South America: Can the petroleum industry pave the way for renewables in Brazil? Energy Policy. 2014;64:58-70.

[24] Chávez-Rodríguez MF, Dias L, Simoes S, Seixas J, Hawkes A, Szklo A, et al. Modelling the natural gas dynamics in the Southern Cone of Latin America. Applied Energy. 2017;201:219-39.

[25] IEA. World Energy Outlook 2016. In: Agency IE, editor. Paris (FR)2016.

[26] EPE. Plano Nacional de Energia - 2050. In: Energética EdP, editor. Rio de Janeiro, Brazil Ministerio de Minas e Energia; 2016. p. 257.

[27] Gomes I. The vanishing LNG Market in Brazil. In: Studies TOIfE, editor.2017.

[28] Parraga M. CERAWEEK-Bolivia seeks new natgas buyers as Petrobras signals cutbacks. Reuters2019.

[29] PETROBRAS. 2030 Strategic Plan and 2014-2018 Business and Management Plan. 2014.

[30] PETROBRAS. 2040 Strategic Plan and 2019-2023 Business and Management Plan. 2018.

[31] Lochner S. Identification of congestion and valuation of transport infrastructures in the European natural gas market. Energy. 2011;36:2483-92.

[32] Dieckhöner C, Lochner S, Lindenberger D. European natural gas infrastructure: The impact of market developments on gas flows and physical market integration. Applied Energy. 2013;102:994-1003.

[33] Gillessen B, Heinrichs H, Hake JF, Allelein HJ. Natural gas as a bridge to sustainability: Infrastructure expansion regarding energy security and system transition. Applied Energy. 2019;251:113377.

[34] Deane JP, Ó Ciaráin M, Ó Gallachóir BP. An integrated gas and electricity model of the EU energy system to examine supply interruptions. Applied Energy. 2017;193:479-90.

[35] Eser P, Chokani N, Abhari R. Impact of Nord Stream 2 and LNG on gas trade and security of supply in the European gas network of 2030. Applied Energy. 2019;238:816-30. 
[36] Hart WE, Laird CD, Watson J-P, Woodruff DL, Hackebeil GA, Nicholson BL, et al.

Pyomo Models and Components: An Introduction. Pyomo - Optimization Modeling in Python. Cham: Springer International Publishing; 2017. p. 47-77.

[37] Cafaro DC, Grossmann IE. Strategic planning, design, and development of the shale gas supply chain network. AIChE Journal. 2014;60:2122-42.

[38] Feijoo F, Huppmann D, Sakiyama L, Siddiqui S. North American natural gas model: Impact of cross-border trade with Mexico. Energy. 2016;112:1084-95.

[39] Feijoo F, Iyer GC, Avraam C, Siddiqui SA, Clarke LE, Sankaranarayanan S, et al. The future of natural gas infrastructure development in the United states. Applied Energy. 2018;228:149-66.

[40] Calvin K, Patel P, Clarke L, Asrar G, Bond-Lamberty B, Cui RY, et al. GCAM v5.1: representing the linkages between energy, water, land, climate, and economic systems. Geosci Model Dev. 2019;12:677-98.

[41] Shaikh F, Ji Q, Shaikh PH, Mirjat NH, Uqaili MA. Forecasting China's natural gas demand based on optimised nonlinear grey models. Energy. 2017;140:941-51.

[42] Zhang Q, Li Z, Wang G, Li H. Study on the impacts of natural gas supply cost on gas flow and infrastructure deployment in China. Applied Energy. 2016;162:1385-98.

[43] Chávez-Rodríguez MF, Garaffa R, Andrade G, Cárdenas G, Szklo A, Lucena AFP. Can Bolivia keep its role as a major natural gas exporter in South America? Journal of Natural Gas Science and Engineering. 2016;33:717-30.

[44] Patrício RA, Sales AD, Sacramento EM, de Lima LC, Veziroglu TN. Wind hydrogen energy system and the gradual replacement of natural gas in the State of Ceará - Brazil. International Journal of Hydrogen Energy. 2012;37:7355-64.

[45] Devlin J, Li K, Higgins P, Foley A. The importance of gas infrastructure in power systems with high wind power penetrations. Applied Energy. 2016;167:294-304.

[46] Qadrdan M, Fazeli R, Jenkins N, Strbac G, Sansom R. Gas and electricity supply implications of decarbonising heat sector in GB. Energy. 2019;169:50-60.

[47] Ameli H, Qadrdan M, Strbac G. Value of gas network infrastructure flexibility in supporting cost effective operation of power systems. Applied Energy. 2017;202:571-80.

[48] Arredondo-Ramírez K, Ponce-Ortega JM, El-Halwagi MM. Optimal planning and infrastructure development for shale gas production. Energy Conversion and Management. 2016;119:91-100.

[49] Börjesson M, Ahlgren EO. Cost-effective biogas utilisation - A modelling assessment of gas infrastructural options in a regional energy system. Energy. 2012;48:212-26.

[50] Samsatli S, Samsatli NJ. A multi-objective MILP model for the design and operation of future integrated multi-vector energy networks capturing detailed spatio-temporal dependencies. Applied Energy. 2018;220:893-920.

[51] Strachan N, Balta-Ozkan N, Joffe D, McGeevor K, Hughes N. Soft-linking energy systems and GIS models to investigate spatial hydrogen infrastructure development in a lowcarbon UK energy system. International Journal of Hydrogen Energy. 2009;34:642-57.

[52] Guillén-Gosálbez G, Mele FD, Grossmann IE. A bi-criterion optimization approach for the design and planning of hydrogen supply chains for vehicle use. AIChE Journal. 2010;56:650-67.

[53] Almansoori A, Shah N. Design and operation of a future hydrogen supply chain: Multiperiod model. International Journal of Hydrogen Energy. 2009;34:7883-97.

[54] Hafsi Z, Elaoud S, Mishra M. A computational modelling of natural gas flow in looped network: Effect of upstream hydrogen injection on the structural integrity of gas pipelines. Journal of Natural Gas Science and Engineering. 2019;64:107-17. 
[55] Reuß M, Grube T, Robinius M, Stolten D. A hydrogen supply chain with spatial resolution: Comparative analysis of infrastructure technologies in Germany. Applied Energy. 2019;247:438-53.

[56] Giarola S, Crow DJG, Hawkes A. Simulating the carbon price trajectory in energy systems with imperfect foresight. In: IEA, editor. 2019 International Energy Workshop. Paris, France2019.

[57] Crow DJG, Giarola S, Hawkes AD. A dynamic model of global natural gas supply. Applied Energy. 2018;218:452-69.

[58] Sachs J, Meng Y, Giarola S, Hawkes A. An agent-based model for energy investment decisions in the residential sector. Energy. 2019;172:752-68.

[59] García Kerdan I, Giarola S, Hawkes A. Implications of Future Natural Gas Infrastructure on Bioenergy Production, Land Use Change and Related Emissions: A Brazil Case Study. In: LA.SDEWES2018, editor. 1st Latin American Conference on Sustainable Development of Energy, Water, and Environment Systems. Rio de Janeiro, Brazil2018.

[60] García Kerdan I, Giarola S, Hawkes A. A novel energy systems model to explore the role of land use and reforestation in achieving carbon mitigation targets: A Brazil case study. Journal of Cleaner Production. 2019;232:796-821.

[61] IBGE. Statistics - Population. In: Estatistica IBdGe, editor. Brazil2019.

[62] GAMS_Development_Corporation. General Algebraic Modeling System (GAMS) Release 24.2.1. Washington, DC, USA2013.

[63] Fricko O, Havlik P, Rogelj J, Klimont Z, Gusti M, Johnson N, et al. The marker quantification of the Shared Socioeconomic Pathway 2: A middle-of-the-road scenario for the 21st century. Global Environmental Change. 2017;42:251-67.

[64] Rochedo PRR, Soares-Filho B, Schaeffer R, Viola E, Szklo A, Lucena AFP, et al. The threat of political bargaining to climate mitigation in Brazil. Nature Climate Change. 2018;8:695-8.

[65] IEA. International Energy Agency Statistics. In: https://www.iea.org/statistics/, editor.2017.

[66] FAO. FAOSTAT. In: http://www.fao.org/faostat/en/\#data, editor.2017.

[67] Rystad. Ucube (upstream database). URL

$<$ https://www.rystadenergy.com/Products/EnP-Solutions/UCube/Default $>$. 2015. 


\section{Appendix}

\section{Appendix A. Grids information}

Table A.1 Grids main information

\begin{tabular}{|c|c|c|c|c|c|c|c|c|}
\hline Grid & Region & State & $\begin{array}{l}\text { LNG } \\
\text { imports }\end{array}$ & $\begin{array}{l}\text { Foreign } \\
\text { natural } \\
\text { gas } \\
\text { imports } \\
\text { (pipeline) }\end{array}$ & $\begin{array}{l}\text { Domestic } \\
\text { natural } \\
\text { gas } \\
\text { imports } \\
\text { (pipeline) }\end{array}$ & $\begin{array}{l}\text { Onshore } \\
\text { natural } \\
\text { gas } \\
\text { production }\end{array}$ & $\begin{array}{l}\text { Biogas } \\
\text { production }\end{array}$ & $\begin{array}{l}\text { Pre-salt } \\
\text { imports }\end{array}$ \\
\hline 1 & $\begin{array}{l}\text { Bolivian border - } \\
\text { Corumba }\end{array}$ & $\begin{array}{l}\text { Mato Grosso } \\
\text { do Sul }\end{array}$ & & $x$ & & & $x$ & \\
\hline 2 & $\begin{array}{l}\text { Campo Grande- } \\
\text { Dourados-Tres } \\
\text { Lagoas }\end{array}$ & $\begin{array}{l}\text { Mato Grosso } \\
\text { do Sul }\end{array}$ & & & & & $x$ & \\
\hline 3 & $\begin{array}{l}\text { Sao Jose Rio } \\
\text { Prieto-Bauru }\end{array}$ & Sao Paulo & & & & $x$ & $x$ & \\
\hline 4 & $\begin{array}{l}\text { Sao Carlos- } \\
\text { Riberao Prieto- } \\
\text { Franca }\end{array}$ & Sao Paulo & & & $x$ & & $x$ & \\
\hline 5 & $\begin{array}{l}\text { Sao Paulo-Santos- } \\
\text { Campinas-Sao } \\
\text { Jose dos Campos }\end{array}$ & Sao Paulo & $x$ & & $x$ & & $x$ & $x$ \\
\hline 6 & Londrina-Maringa & Parana & & & & $x$ & $x$ & $\lambda$ \\
\hline 7 & Curitiba-Ponta & Parana & & & & & & \\
\hline 8 & $\begin{array}{l}\text { Grossa } \\
\text { Cascavel-Foz de } \\
\text { Iguazu }\end{array}$ & Parana & $x$ & & & & $\begin{array}{l}x \\
x\end{array}$ & $x$ \\
\hline 9 & $\begin{array}{l}\text { Florianopolis- } \\
\text { Joinville- }\end{array}$ & Santa Catarina & & & & & & \\
\hline 10 & $\begin{array}{l}\text { Blumenau } \\
\text { Porto Alegre- }\end{array}$ & Rio Grande do & $x$ & & & & $x$ & $x$ \\
\hline 11 & $\begin{array}{l}\text { Caixas do Sul } \\
\text { Pelotas-Rio } \\
\text { Grande-Sao } \\
\text { Leoplodo- }\end{array}$ & $\begin{array}{l}\text { Sul } \\
\text { Rio Grande do } \\
\text { Sul }\end{array}$ & $x$ & & & & $x$ & $x$ \\
\hline 12 & $\begin{array}{l}\text { Alvorada } \\
\text { Argentinian } \\
\text { border - Santa }\end{array}$ & $\begin{array}{l}\text { Rio Grande do } \\
\text { Sul }\end{array}$ & $x$ & & & & $\mathrm{x}$ & $x$ \\
\hline 13 & $\begin{array}{l}\text { Maria } \\
\text { Pre-Salt } \\
\text { Production }\end{array}$ & Santos Basin & & $x$ & & & $x$ & \\
\hline
\end{tabular}


Table A.2 Distance between grids distance (centroid to centroid)

1

2

3

4

5

6

7

8

9

10

11

12

13

14

15

16

17

18

19

\begin{tabular}{lll}
\hline From & To & kilometres \\
\hline 1 & 2 & 360 \\
2 & 3 & 568 \\
2 & 6 & 455 \\
3 & 4 & 152 \\
3 & 5 & 382 \\
3 & 7 & 430 \\
4 & 5 & 284 \\
5 & 7 & 379 \\
6 & 7 & 294 \\
6 & 8 & 330 \\
7 & 8 & 445 \\
7 & 9 & 266 \\
8 & 12 & 667 \\
9 & 10 & 387 \\
9 & 12 & 867 \\
10 & 11 & 249 \\
10 & 12 & 568 \\
11 & 12 & 536
\end{tabular}




\section{Appendix B. MUSE modelling framework}

Figure A.1 illustrates the generic MUSE modelling framework. In its modular architecture, MUSEBrazil includes supply sectors (upstream oil, upstream gas, coal extraction, renewables uptake, uranium uptake); conversion sectors (power sector, refinery, bio-refinery) as well as demand sectors (agriculture, buildings, industry, transport).

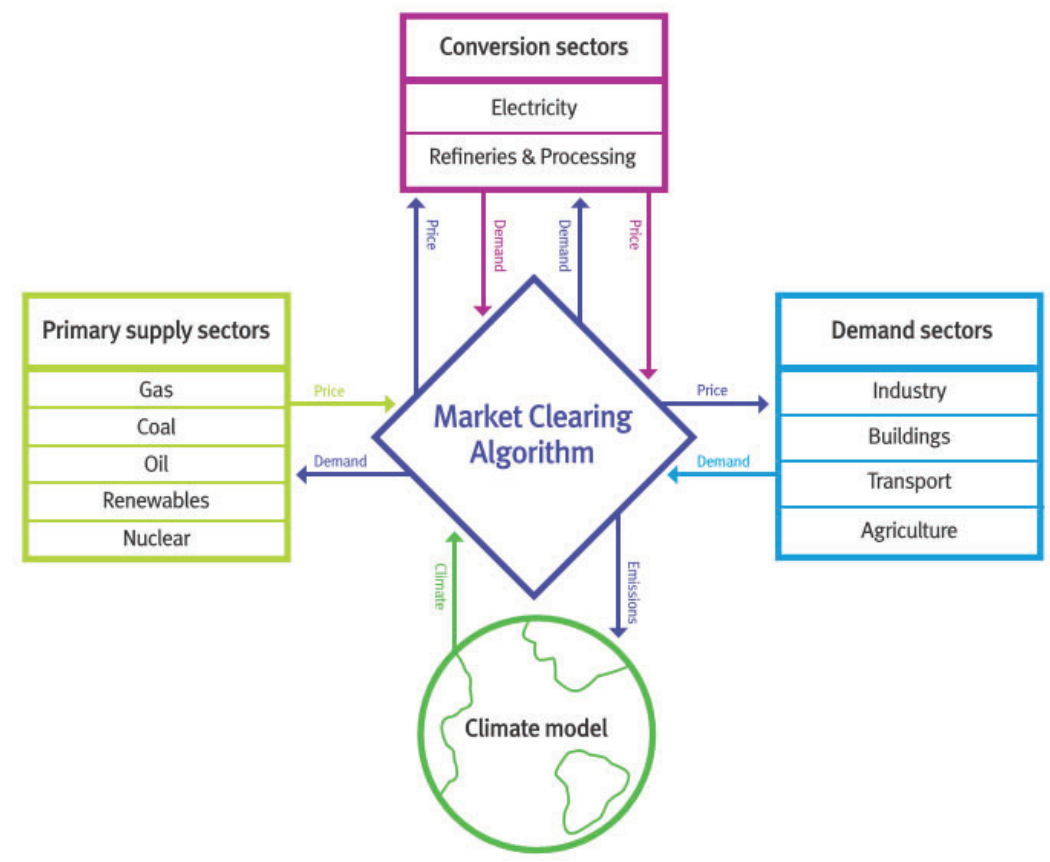

Figure B.1 MUSE model architecture and modules interactions

The energy equilibrium of MUSE is given by the market clearing algorithm (MCA) which connects all parts of the model and is responsible for the information flow between all sectors. The solution algorithm of MUSE is given by an inner loop for each time period and an outer loop for the simulation horizon (e.g. 2050 or 2100). The MCA iterates between sector modules until price and quantity of each energy commodity converge.

\section{Appendix C. Supply Chain Model}

\section{Objective function}

The objective function minimises the total discounted cost for the whole system:

$$
\min _{\text {s.t. }} T D C=\sum_{t} \frac{T C_{t}}{(1+r)^{t-1}}
$$

Where $T C_{t}$ is the total system cost in each time period Total cost per period: 


$$
\begin{aligned}
T C_{t}=P R C C_{t}+ & T C C_{t}+T R C C_{t}+P G C C_{t}+S C C_{t} \\
& +\left(\text { PROC }_{t}+\text { TOC }_{t}+\text { TROC }_{t}+P G O C_{t}+S O C_{t}+I C_{t}-E R_{t}\right) \\
& \cdot \text { Duration }_{t}
\end{aligned}
$$

\section{Cost components}

Capital cost of production of unprocessed natural gas:

$$
P R C C_{t}=\sum_{g, i p r} U P r C C_{g i p r t} \cdot m \cdot V R_{g \text { ipr } t_{0}} \cdot Z 1_{g \text { ipt } t}
$$

Operating cost of production of unprocessed natural gas:

$$
\begin{gathered}
\text { PROC }_{t}=\sum_{g, i p r}\left(Z 5_{g \text { ipr } t} \cdot U_{\text {PrOCa }} \text { ipr } t\right. \\
\left.\cdot A P_{\text {gipr } t}\right)
\end{gathered}
$$

Capital cost of infrastructure for transmission, which includes pipelines and pumping stations:

$$
\begin{gathered}
\operatorname{TCC}_{t}=\sum_{g, g^{\prime}, i}\left(\operatorname{UTCCa}_{\text {i isf } t} \cdot Y 1_{g t}+U T C C b_{g g^{\prime} i} \cdot \frac{N P A_{g g^{\prime} i}}{2} \cdot \operatorname{CapP}_{i}\right. \\
\left.\cdot \text { DistanceP }_{g g^{\prime}}\right)
\end{gathered}
$$

Operating cost of transmission:

$$
\begin{gathered}
\operatorname{TOC}_{t}=\sum_{g, g^{\prime}, i}\left(U T O C a_{g g^{\prime} i} \cdot Y 2_{g t}+U T C O \operatorname{Cob}_{g^{\prime} i} \cdot \text { DistanceP }_{g g^{\prime}}\right. \\
\left.\cdot Q P_{g g^{\prime} i t}\right)
\end{gathered}
$$

Capital cost of new transport units:

$$
T R C C_{t}=\sum_{g, i t r} U T r C C_{i t r} \cdot N T P_{g i t r t}
$$


Operating cost of transport:

$$
\begin{aligned}
& \text { TROC }_{t}=\sum_{g, g^{\prime}, i, i t r}\left(U T r O C a_{i t r} \cdot A N T_{g i t r t}+U T r O C b_{i t r t} \cdot \frac{C T J_{g} g^{\prime} i \text { itrt } t}{\operatorname{CapTr}_{\text {itr }}}\right. \\
& \left(\frac{\text { OpTime }}{2 \cdot \frac{\text { DistanceF }_{g g^{\prime}} \text { itr }}{\text { AvSpeed }_{\text {itr }}}+\text { LUTime }_{\text {itr }}}\right) \cdot 2 \\
& \text { - DistanceF } \left.{ }_{g} g^{\prime} \text { itr }\right)
\end{aligned}
$$

Capital cost of infrastructure of processing facilities:

$$
\begin{gathered}
P G C C_{t}=\sum_{g, i p g}\left(U P g C C a_{i p g t} \cdot N P G_{g i p g t}+U P g C C b_{i p g t}\right. \\
\left.\cdot C E P G_{g i p g t}\right)
\end{gathered}
$$

Operating cost of processing facilities:

$$
\begin{gathered}
P G O C_{t}=\sum_{g, i p g}\left(U P g O C a_{i p g t} \cdot C P G_{g i p g t}+U P g O C b_{i p g t} t\right. \\
\left.\cdot P G R_{g i p g t}\right)
\end{gathered}
$$

Capital cost of storage infrastructure:

$$
\begin{gathered}
S C C_{t}=\sum_{g, i s f, i}\left(U S C C a_{i \text { isf } t} \cdot N S_{g i \text { isf } t}+U S C C b_{i \text { isf } t} \cdot(1-b)\right. \\
\left.\cdot C A P E S_{\text {gi isf } t}\right)
\end{gathered}
$$

Operating cost of storage infrastructure: 


$$
\begin{gathered}
\operatorname{SOC}_{t}=\sum_{g, \text { isf }, t}\left(\operatorname{USCOCa}_{i \text { isf } t} \cdot(1-b) \cdot \text { CAPS }_{\text {gi isf } t}+U_{\text {SCOCb }} \text { isf } t\right. \\
\left.\cdot\left(V S_{g \text { i isf } t}-b \cdot \text { CAPS }_{\text {gi isf } t}\right)\right)
\end{gathered}
$$

Costs of imports:

$$
I C_{t}=\sum_{g, i} U_{n i t} C_{g i t} \cdot Q I_{g i t}
$$

Export revenues:

$$
E R_{t}=\sum_{g, i} \text { UnitC }_{g i t} \cdot Q E_{g i t}
$$

\section{Production}

Each production facility can be built only once in the modelled time horizon:

$$
\sum_{t} Z 1_{\text {giprt }} \leq 1 \quad \forall g, \text { ipr }
$$

A production facility can exist in a given year if it was previously built:

$$
Z 5_{g_{\text {ipr } t}}=Z 5_{\text {gipr } t-1}+Z 1_{\text {giprt }} \quad \forall g, \text { ipr }, t \geq 2
$$

A production facility can only operate if it exists in a given year:

$$
Z 2_{\text {gipr } t} \leq Z 5_{\text {gipr } t} \quad \forall g, \text { ipr }, t \geq 2
$$

Production rate is bounded by a big-M constraint to ensure there can only be production if the site is operational:

$$
A P_{\text {gipr } t} \leq Z 2_{\text {gipr } t} \cdot \mathrm{M} \quad \forall g, i p r, t
$$

Production rate is bounded by available reserves in the production facility: 


$$
A P_{\text {gipr } t} \leq m \cdot V R_{\text {gipr } t} \quad \forall g, i p r, t
$$

Link between available reserves and how much was produced in the last time period:

$$
V R_{\text {gipr }_{t}}=V R_{\text {gipr } t-1-A P_{\text {ipr } t-1} \cdot \text { Duration }_{t} \quad \forall g, \text { ipr }, t}
$$

Allowing for production sites to change their operational status between one time period to the next, and ensuring these changes are reflected in variables $Z 3_{g \text { ipr } t}$ and $Z 4_{\text {g ipr } t}$ :

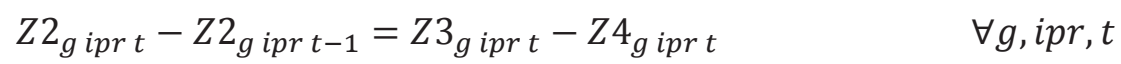

Operational status can only change in one direction between time periods:

$$
Z 3_{\text {gipr } t}+Z 4_{\text {gipr } t} \leq 1 \quad \forall g, i p r, t
$$

\section{Transmission}

Each pumping station can be built only once in the modelled time horizon:

$$
\sum_{t} Y 1_{g t} \leq 1
$$

A pumping station can exist in a given year if it was previously built:

$$
Y 2_{g t}=Y 2_{g t-1}+Y 1_{g t} \quad \forall g, t \geq 2
$$

There can only be a flow of gas type $i$ between zone $g$ and zone $g^{\prime}$ if there is a pumping station installed in zone $g$ :

$$
Y 3_{g g^{\prime} i t} \leq Y 2_{g t} \quad \forall g, g^{\prime}, i, t
$$

Flow can go in only one direction through each pipeline, and there cannot be flow between a zone and itself:

$$
Y 3_{g g^{\prime} i t}+Y 3_{g^{\prime} g i t} \leq 1
$$




$$
Y 3_{g g^{\prime} i t}=0 \quad \forall i, t, g=g^{\prime}
$$

Coupling of the continuous variable for flow between zones to the binary variable that describes whether there is a flow of gas $i$ between two zones:

$$
\frac{Y 3_{g g^{\prime} i t}}{M 1} \leq Q P_{g g^{\prime} i t} \leq Y 3_{g g^{\prime} i t} \cdot \mathrm{M} 1 \quad \forall g, g^{\prime}, i, t
$$

The total gas flow is bounded by the total pipeline capacity between zones:

$$
Q P_{g g^{\prime} i t} \leq N P_{g g^{\prime} i t} \cdot \operatorname{CapP}_{i} \quad \forall g, g^{\prime}, i, t
$$

The number of pipelines for gas type $i$ in a given time period is the number of pipes in the previous time period, plus the ones that were added:

$$
N P_{g g^{\prime} i t}=N P_{g g^{\prime} i t-1}-N P A_{g g^{\prime} i t} \quad \forall g, g^{\prime}, i, t
$$

Pipes can be used in either direction:

$$
N P A_{g g^{\prime} i t}=N P A_{g^{\prime}} g \text { it } \quad \forall g, g^{\prime}, i, t
$$

\section{Freight transport}

Total flow rate transported by each freight transport mode:

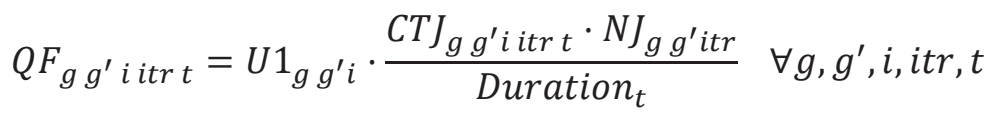

Total number of transport units available for transporting gas from each zone:

$$
0 \leq \sum_{g^{\prime}, i} \frac{\text { TTJ }_{g} g^{\prime} i \text { itr } t}{\text { CapTr }_{\text {itr }}} \leq A N T_{\text {gitr } t} \quad \forall g, i t r, t
$$

Allows for purchasing additional transport units:

$$
A N T_{g_{\text {itr } t}}=A N T_{g_{\text {itr } t-1}}+N T P_{\text {gitr } t} \quad \forall g, \text { itr }, t \geq 2
$$


Bounds number of additional units that can be purchased:

$$
0 \leq N T P_{\text {gitr } t} \leq \operatorname{MaxNTr} P_{\text {itr }} \quad \forall g, \text { itr }, t
$$

\section{Processing}

Processing facilities can be built in each zone, and processing rates are constrained:

$$
P G_{\text {gipg } t} \leq C P G_{\text {gipg } t} \quad \forall g, \text { ipg }, t
$$

Maximum value for processing rates can be expanded:

$$
C P G_{\text {gipg } t}=C P G_{g \text { ipg } t-1}+C E P G_{\text {gipg } t} \quad \forall g, i p g, t \geq 2
$$

Total expanded capacity is constrained by minimum and maximum number of production facilities that can be installed in each time period:

$$
\begin{aligned}
\text { MinCapPG }_{\text {ipg }} \cdot & N P G_{\text {gipg } t} \leq C E P G_{\text {gipg } t} \\
& \leq M a x C a p P G_{i p g} \cdot N P G_{g i p g} t \quad \forall g, i t r, t
\end{aligned}
$$

Processing facilities can be built only if there is sufficient infrastructure to support them:

$$
N P G_{\text {gipg } t} \leq V i_{\text {gipg }} \cdot \mathrm{M} 1 \quad \forall g, i p g, t
$$

\section{Storage}

Balance of stored gas between time periods:

$$
\begin{gathered}
V S_{g i \text { isf } t}=V S_{g \text { i isf } t-1}+\left(\text { QSIN }_{g \text { i isf } t-1}-\text { QSOUT }_{\text {gi isf } t-1}\right) \\
\cdot \text { Duration }_{t} \forall g, i, i s f, t
\end{gathered}
$$

Inflow and outflow variables coupled with the binary variables:

$$
\frac{W I N_{g i \text { isf } t}}{M 1} \leq Q S I N_{g i \text { isf } t} \leq W I N_{g i \text { isf } t} \cdot M 1 \quad \forall g, i, i s f, t
$$




$$
\frac{\text { WOUT }_{\text {gi isf } t}}{M 1} \leq \text { QSOUT }_{\text {gi isf } t} \leq \text { WOUT }_{\text {gi isf } t} \cdot M 1 \quad \forall g, i, \text { isf }, t
$$

Gas is either being added or removed from each storage facility in each time period:

$$
\text { WIN }_{\text {gi isf } t}+\text { WOUT }_{\text {gi isf } t} \leq 1 \quad \forall g, i, \text { isf }, t
$$

The stored volume in each facility is bounded by the maximum capacity of the facility and by a buffer capacity

$$
b \cdot \text { CAPS }_{\text {gi isf } t} \leq V S_{\text {gi isf } t} \leq C A P S_{g i \text { isf } t} \quad \forall g, i, \text { isf }, t
$$

Ensuring that a fraction of the demand for subsequent time period is stored to allow for demand shocks, considering the densities of different gas forms.

$$
c \cdot \sum_{g} \text { Demand }_{g t} \cdot \text { Duration }_{t} \leq \sum_{g, i, i \text { f } f} \frac{\rho_{i}}{\rho_{N G}} \cdot V S_{g i \text { isf } t} \quad \forall t
$$

Maximum storage capacity can be expanded between time periods:

$$
\text { CAPS }_{\text {gi isf } t}=\text { CAPS }_{g i \text { isf } t-1}+\text { CAPES }_{\text {gi isf } t} \quad \forall g, i, \text { isf }, t
$$

Expansion capacity is bounded:

$$
\operatorname{MinCapS}_{\text {isf }} \cdot N S_{\text {gi isf } t} \leq \mathrm{CAPES}_{\text {gisf } t} \leq \operatorname{MaxCapS}_{\text {isf }} \cdot N S_{g i \text { isf } t} \quad \forall g, i, \text { isf }, t
$$

There can only be storage facilities where the zone supports the infrastructure required for storing:

$$
N S_{\text {gi isf } t} \leq W i_{\text {gisf }} \cdot M 1 \quad \forall g, i, \text { isf }, t
$$

\section{Material balances}

Material balances for each form of gas:

$$
\sum_{g^{\prime}} Q P_{g^{\prime} g N G t}+\sum_{g^{\prime}, i t r} Q F_{g^{\prime} g N G i t r t}+Q I_{g N G t}-
$$




$$
\sum_{g^{\prime}} Q P_{g^{\prime} g L N G t}+\sum_{g^{\prime}, i t r} Q F_{g^{\prime} g L N G i t r t}+Q I_{g L N G t}-
$$$$
\sum_{g^{\prime}} Q P_{g g^{\prime} L N G t}-\sum_{g^{\prime}, i t r} Q F_{g g^{\prime} L N G i t r t}-Q E_{g L N G t}+
$$$$
P G R_{g L F} t-\frac{\rho_{N G}}{\rho_{L N G}} \cdot P G R_{g R G}+
$$$$
\sum_{i s f}\left(Q S O U T_{g L N G} \text { isf } t-\operatorname{QSIN}_{g L N G \text { isf } t}\right)-\text { Demand }_{g L N G t}=0 \quad \forall g, t
$$

$\sum_{g^{\prime}} Q P_{g^{\prime} g U P t}-\sum_{g^{\prime}} Q P_{g v g^{\prime} U P t}+\sum_{i p r} A P_{g i p r t}-\frac{\rho_{N G}}{\rho_{U P}} \cdot P G R_{g N G P t}=0 \quad \forall g, t$

Biogas production bounded by maximum allowable biogas fraction in gas streams:

$$
P G R_{g B G P} \leq \frac{f b g}{1-f b g} \cdot P G R_{g N G P t} \quad \forall g, t
$$

A zone can only be importing or exporting in each time period:

$$
X 1_{g i t}+X 2_{g i t} \leq 1 \quad \forall g, i, t
$$

Imports and exports are bounded, and the binary variables of whether a zone is importing/exporting are linked to the import/export gas flows:

$$
\begin{aligned}
& X 1_{g i t} \cdot \operatorname{MinQI}_{\text {git }} \leq Q I_{\text {git }} \leq X 1_{\text {git }} \cdot \operatorname{MaxQI}_{\text {git }} \quad \forall g, i, t \\
& X 2_{g i t} \cdot \operatorname{MinQE}_{\text {it }} \leq Q E_{\text {git }} \leq X 2_{g i t} \cdot \operatorname{Max}_{E_{\text {git }}} \quad \forall g, i, t
\end{aligned}
$$

